DAS ALTERSVORSORgE-VERHALTEN VON SELBSTÄNDIGEN - EINE ANALYSE AUF BASIS DER SAVE-DATEN

Michael Ziegelmeyer 


\title{
Das Altersvorsorge-Verhalten von Selbständigen - eine Analyse auf Basis der SAVE-Daten ${ }^{1}$
}

\author{
Michael Ziegelmeyer ${ }^{\dagger}$
}

August 2009

\begin{abstract}
Da etwa 3/4 aller Selbständigen nicht durch ein obligatorisches Altersvorsorgewerk abgesichert sind, stellt sich die Frage, inwieweit Altersarmut für diese Selbständigen zum Problem werden könnte. Eine eingehende Untersuchung des Altersvorsorge-Verhaltens von Selbständigen erscheint daher notwendig. Das SAVE Panel von 2005-2008 bietet eine neue und bisher ungenutzte Datengrundlage, um die Vorsorgefähigkeit, die Vorsorgebereitschaft und das Vorsorgeniveau abzuschätzen.
\end{abstract}

Die Auswertungen zeigen, dass dem größten Teil der Selbständigen ausreichende Mittel für eine entsprechende Altersvorsorge zur Verfügung stehen, so dass für diese Gruppe Altersarmut ausgeschlossen sein dürfte. Allerdings sind mindestens $10 \%$ der Haushalte mit selbständigem Haupteinkommensbezieher nicht in der Lage, aus ihrem Nettoeinkommen einen ausreichend großen Betrag zu sparen, der ein Alterseinkommen auf dem Niveau der Grundsicherung im Alter sicherstellt. Auch wenn Haushalte mit selbständigem Haupteinkommensbezieher im Schnitt mehr sparen als Haushalte mit abhängig beschäftigtem Haupteinkommensbezieher, so sorgen Selbständige in den unteren Einkommensbereichen im Schnitt weniger vor als abhängig Beschäftigte, obwohl bei diesen bereits Beiträge zur Rentenversicherung abgeführt werden, die nicht in die Berechnung ihrer Sparquote eingehen. Beim Nettogesamtvermögen von Haushalten (ohne Berücksichtigung der Anwartschaften der Ersten Säule der Alterssicherung) haben Selbständige im Mittel ein dreimal höheres Vermögen als abhängig Beschäftigte. Jedoch trägt die private Altersvorsorge bei Selbständigen im Schnitt nur knapp über 4\% zum Nettogesamtvermögen bei. In der Altersklasse über 55 Jahre, können, ohne Berücksichtigung von Verhaltensänderungen sowie der in obligatorischen Altersvorsorgewerken erworbenen Anwartschaften, 26\% der Haushalte mit selbständigem Haupteinkommensbezieher den Vermögensbedarf zur Deckung der Grundsicherung im Alter nicht aufbringen.

JEL: H55, E21, D31, J26

Schlagwörter: Altersvorsorge, Selbständige, Sparverhalten, Armut

\footnotetext{
${ }^{1}$ Für finanzielle Unterstützung sei dem Land Baden-Württemberg und dem Gesamtverband der Deutschen Versicherungswirtschaft gedankt, der DFG für die Finanzierung der SAVE-Daten. Ein großes Dankeschön an Martin Gasche für die Begleitung dieses Projektes. Axel Börsch-Supan, Franziska Fiebig, Anette Reil-Held, Ulrich Schlieper und die Teilnehmer der FNA-Tagung sowie des MEA Seminars haben durch ihre wertvollen Kommentare diese Arbeit bereichert.

† Mannheimer Forschungsinstitut Ökonomie und Demographischer Wandel (MEA); Universität Mannheim; L13,17; 68131 Mannheim; E-Mail: Ziegelmeyer@mea.uni-mannheim.de
} 


\section{Einführung}

Seit geraumer Zeit wird in Politik und Wissenschaft diskutiert, inwieweit Armut für nicht obligatorisch abgesicherte Selbständige im Alter zu einem Problem werden könnte (Windhövel et al., 2008; Rische, 2008). Während die Pflichtversicherung für große Teile der Bevölkerung hilft Altersarmut zu verhindern, so lässt die Versicherungsfreiheit für einen großen Teil der Selbständigen vermuten, dass bei diesem Personenkreis das Problem der zu geringen Vorsorge für das Alter und die damit verbundene mögliche Altersarmut ein weitaus größeres Problem darstellt. ${ }^{2}$ Zudem hat sich die Anzahl der Soloselbständigen allein von 1991 auf 2005 auf 2,29 Mio. nahezu verdoppelt (Sachverständigenrat, 2006/07). Gerade bei dieser Gruppe wird eine mangelnde finanzielle Fähigkeit zur Vorsorge vermutet. Zudem führen die immer flexibleren Erwerbsverläufe mit Wechsel in die Selbständigkeit und aus derselben heraus zu einer „Durchlöcherung“ der individuellen Versicherungshistorie, was die Ansprüche in den obligatorischen Versorgungswerken mindert (Schulze Buschoff, 2007, S. 16). Zur Verhinderung oder zumindest Abschwächung von Altersarmut wird vorgeschlagen sowohl den Pflichtversichertenkreises der Gesetzlichen Rentenversicherung (GRV) auszuweiten, als auch eine private Pflichtversicherung für Selbständige einzuführen.

In der laufenden Diskussion wird das „Altersarmutsargument“ oftmals pauschal herangezogen. Ein genauer Nachweis über die Größe der Problematik fehlt. Im Rahmen eines solchen Nachweises sollte in erster Linie die Frage behandelt werden, ob die nicht obligatorisch abgesicherten Selbständigen in der Lage sind, aus ihrem eventuell geringen Einkommen für das Alter ausreichend vorzusorgen (Vorsorgefähigkeit). Darauf aufbauend stellt sich die Frage, ob Selbständige, wenn sie denn ein ausreichendes Einkommen zur Verfügung haben, tatsächlich bereit sind, einen Teil davon für das Alter zurückzulegen (Vorsorgebereitschaft). Abschließend müssen die direkten und indirekten Altersvorsorgemaßnahmen der Selbständigen evaluiert werden, um eine valide Aussage darüber zu treffen, wie viele von ihnen von Altersarmut bedroht sind (Vorsorgeniveau).

Bisher stehen zur Beantwortung der aufgeworfenen Fragen in den verschiedenen Datensätzen nur sehr lückenhaft Informationen über Selbständige zur Verfügung. Der SAVE Paneldatensatz 20052008 ermöglicht es, diese Fragen umfassend zu analysieren, da in SAVE detaillierte Fragen zu Einkommen, Ersparnis, Vermögen sowie zur Altersvorsorge zusammen mit einer großen Band-

\footnotetext{
${ }^{2}$ Verschiedene Quellen (Kohlmeier, 2009, S. 22; Fachinger/Oelschläger/Schmähl, 2004, S.230 f.) beziffern den Anteil der Anfang des 21. Jahrhunderts durch ein obligatorisches Versorgungswerk (in GRV pflichtversichert, Alterssicherung der Landwirte, Berufsständische Vorsorgungswerke) abgesicherten Selbständigen auf etwa $1 / 4$ aller selbständig Tätigen.
} 
breite von soziodemographischen Variablen enthalten sind. Zudem erlaubt das Panel Verhaltensänderungen über die Zeit zu beobachten und die Zeitpunktbetrachtung einer Querschnittsanalyse auf einen längeren Zeitraum des Lebenszyklus der Personen und Haushalte auszudehnen.

Das vorliegende Diskussionspapier analysiert die Vorsorgefähigkeit, gemessen am Einkommen, die Vorsorgebereitschaft, gemessen anhand der jährlichen Ersparnis, und das Vorsorgeniveau, gemessen durch das direkte und indirekte Altersvorsorgevermögen, von Selbständigen mit dem SAVE Paneldatensatz 2005-2008 in einer deskriptiven Weise und stellt damit den ersten Schritt zu einer umfassenden Evaluierung des Altersvorsorge-Verhaltens von Selbständigen dar. Mindestens $10 \%$ der Haushalte mit selbständigem Haupteinkommensbezieher sind nicht in der Lage, aus ihrem Nettoeinkommen einen ausreichend großen Betrag zu sparen, der ein Alterseinkommen auf dem Niveau der Grundsicherung im Alter sicherstellt. Auch wenn Haushalte mit selbständigem Haupteinkommensbezieher im Schnitt mehr sparen als Haushalte mit abhängig beschäftigten Haupteinkommensbezieher, so sorgen Selbständige in den unteren Einkommensbereichen im Schnitt weniger vor als abhängig Beschäftigte, obwohl bei abhängig Beschäftigten bereits Beiträge zur Rentenversicherung abgeführt werden, die nicht in die Berechnung ihrer Sparquote eingehen. Beim Nettogesamtvermögen von Haushalten (ohne Berücksichtigung der Anwartschaften der Ersten Säule der Alterssicherung) haben Selbständige im Mittel ein dreimal höheres Vermögen als abhängig Beschäftigte. Erstaunlich ist, dass bei Selbständigen die private Altersvorsorge im Schnitt nur knapp über 4\% zum Nettogesamtvermögen beiträgt. In der Altersklasse über 55 Jahre können 26\% der Haushalte mit selbständigem Haupteinkommensbezieher den Vermögensbedarf zur Deckung der Grundsicherung im Alter nicht aufbringen, wenn Verhaltensänderungen sowie die in obligatorischen Altersvorsorgewerken erworbenen Anwartschaften unberücksichtigt bleiben.

Das Papier ist wie folgt aufgebaut: Im zweiten Abschnitt werden die theoretischen Grundlagen des Sparens für das Alter erläutert, die einem „ausreichenden“ Vermögensaufbau für das Alter entgegenstehen. Auf die bereits bestehende Literatur, die sich mit verschiedenen (Teil-)Aspekten des Altersvorsorge-Verhaltens von Selbständigen in Deutschland beschäftigt, wird in Abschnitt 3. eingegangen. Abschnitt 4. stellt den verwendeten SAVE Datensatz 2005-2008 vor. Die Ergebnisse werden im fünften Abschnitt dargelegt und diskutiert. Abschließend wird in Abschnitt 6. ein Resümee gezogen. 


\section{Theoretischer Hintergrund}

Der theoretische Rahmen für das Altersvorsorgemotiv geht zurück auf die klassische Lebenszyklustheorie (Modigliani/Brumberg, 1954; Friedman, 1957). Konsum und Sparentscheidungen sind das Ergebnis eines wohl definierten intertemporalen Maximierungsproblems. Eine zentrale Annahme ist dabei die Unterstellung rationaler und vorausschauender Individuen. Geht man ferner von den üblichen Annahmen für die Nutzenfunktion sowie von einem Einkommenspfad aus, der bei Renteneintritt auf null fällt oder zumindest stark abgesenkt wird, werden diese rationalen Individuen Vermögen bis zum Renteneintritt ansparen, um durch Vermögensabbau während der Rentenzeit den Konsum über die komplette Lebensspanne zu glätten.

Jedoch können diverse Gründe einem vor Altersarmut schützenden Vormögensaufbau im Wege stehen, die oftmals rechtfertigend für die Einführung einer Altersvorsorgepflicht(versicherung) herangezogen werden. So kann ein Haushalt oder ein Individuum durch negative Einkommensschocks lange Zeit geringe Einkommen haben. Dies kann zu einer vollständigen Konsumierung des Einkommens während des Erwerbslebens führen, ohne dass etwas für das Alter gespart wird. Die Folge dieser fehlenden Vorsorgefähigkeit kann darin bestehen, dass im Alter der Konsum eventuell drastisch absinkt oder der Renteneintritt verzögert wird. Setzt man die Vorsorgefähigkeit der Haushalte durch ein ausreichendes Einkommen voraus, gibt es zwei theoretisch denkbare Gründe, Diskontierung zukünftigen Konsums und fehlendes finanzielles Wissen, aus denen Haushalte nicht genügend für ihr Alter vorsorgen. Ein weiterer Grund für einen aus gesellschaftlicher Sicht nicht ausreichenden Vermögensaufbau, ist das Trittbrettfahrerverhalten. Diese drei Gründe werden anschließend kurz diskutiert.

In Lebenszyklusmodellen wird in der Regel von einer exponentiellen Diskontierung zukünftigen Nutzens ausgegangen. Verschiedene Simulationen und Experimente (siehe z.B. Frederick et al., 2002; Soman et al., 2005; Laibson et al., 2007) haben jedoch gezeigt, dass eine hyperbolische bzw. quasi-hyperbolische Diskontierung individuelles Verhalten besser abbildet. Sowohl bei der hyperbolischen als auch bei der quasi-hyperbolischen Diskontierung kommt es zu zeitinkonsistenten Entscheidungen. Eine beispielsweise vor 100 Tagen getroffene Entscheidung über ein Ereignis in 101 Tagen wird nach 100 Tagen zu Gunsten einer kurzfristigen Versuchung verändert. Unter anderem führt solches Verhalten zu einer unzureichenden Konsumglättung über den Lebenszyklus und bietet eine Erklärung dafür, warum Haushalte aktuell zu wenig vorsorgen, obwohl eine höhere Vorsorge langfristig als optimal angesehen wird. 
Ein weiterer Grund für heterogenes Sparverhalten liegt im unterschiedlichen Grad des Finanzwissens von Haushalten. Lusardi und Mitchell (2009) legen anhand des American Life Panels dar, dass höheres Finanzwissen mit einer intensiveren Rentenplanung einhergeht. Die intensivere Rentenplanung selbst wurde als starker Einflussfaktor auf die Vermögensbildung identifiziert (Lusardi, 1999, 2003; Lusardi/Mitchell, 2007; Lusardi/Beeler, 2007). Bucher-Koenen (2009) zeigt für Deutschland, dass Personen mit geringerem finanziellem Wissen unregelmäßigeres Sparverhalten aufweisen und seltener eine privaten Altersvorsorgevertrag abschließen. Die Ergebnisse deuten darauf hin, dass Haushalte mit geringem Finanzwissen ihren Vermögensaufbau eventuell vernachlässigen und so zu wenig für das Alter vorsorgen.

Der letzte aufgeführte Grund liegt in den institutionellen Rahmenbedingungen Deutschlands begründet. Der deutsche Staat sichert allen Personen, deren gewöhnlicher Aufenthalt im Inland ist, eine bedürftigkeitsorientierte Grundsicherung im Alter zu (SGB XII, 4 Kapitel). Diese Absicherung begünstigt Trittbrettfahrerverhalten von Individuen. Da im Alter die durch den Staat zugesicherte Grundsicherung einen gewissen Konsum auf Kosten der Gesellschaft erlaubt, kann es aus individueller Sicht optimal sein, während des Erwerbslebens das Einkommen komplett zu konsumieren und im Alter auf die Ressourcen der Allgemeinheit zurückzugreifen. Durch die Grundsicherung im Alter werden Sparanreize vermindert, da das Vermögen die Höhe der Grundsicherung reduziert. Die Grundsicherungszahlungen müssen ihrerseits aus dem Steueraufkommen finanziert werden, was seinerseits mit Zusatzlasten verbunden ist. ${ }^{3}$

\section{Ausgewählte Literatur}

Eine Reihe von Papieren beschäftigt sich mit der Vorsorgefähigkeit von Selbständigen anhand des Einkommens. Sowohl Merz (2006) mit einer Analyse der Einkommenssteuerstatistik wie auch Kohlmeier (2009) auf Basis der EVS 2003 und des Mikrozensus 2006 oder das Gutachten des Sachverständigenrates (Gutachten des Sachverständigenrates für das Jahr 2006/07, Ziffern 352355) mit dem Mikrozensus 2005 kommen zu dem Schluss, dass die Einkommen der selbständigen Haupteinkommensbezieher deutlich ungleicher verteilt sind als die der abhängig beschäftigten Haupteinkommensbezieher. Einem großen Teil der Selbständigen steht ein nur geringes Einkommen zur Verfügung. Dabei handelt es sich zu einem großen Teil um Soloselbständige, wie anhand des Mikrozensus 2005 und 2006 gezeigt wird. Fachinger (2002) ${ }^{4}$ findet durch eine Auswertung der EVS von 1998, dass sich die Vorsorgefähigkeit der Selbständigen im Durchschnitt kaum von

\footnotetext{
${ }^{3}$ Siehe dazu Breyer und Buchholz (2007, S. 148 ff.).

${ }^{4}$ Die gleichen Ergebnisse finden sich in Fachinger, Oelschläger, Schmähl (2004).
} 
der der abhängig Beschäftigten unterscheidet. Allen diesen Analysen ist die Beurteilung gemein, dass unter Beachtung der Einschränkungen der verwendeten Datensätze die Gefahr von Altersarmut für einen nicht unerheblichen Teil der Selbständigenpopulation besteht.

Das Vorsorgeniveau wird von Kohlmeier (2009) untersucht. Sie vergleicht AVID 2005, ASID 2003 und die EVS 2003 auf direkte und indirekte Maßnahmen zur Altersvorsorge. ${ }^{5}$ Sie konstatiert, dass ein erheblicher Teil der nicht obligatorisch abgesicherten Selbständigen nicht ausreichend indirekt für das Alter vorsorgen dürfte, allerdings ohne die direkten Maßnahmen in die Betrachtung einbeziehen zu können. Damit deuten die Aussagen der Vorsorgefähigkeits- und Vorsorgeniveauanalyse in eine Richtung.

Zusammenfassend lässt sich sagen, dass sich die bisherige Literatur ${ }^{6}$ über das AltersvorsorgeVerhalten von Selbständigen in Deutschland auf Teilaspekte der in Abschnitt 1 beschriebenen Fragen beschränkt hat. Ein umfassendes Bild konnte bisher durch die eingeschränkte Datenlage nicht gezeichnet werden. Einen Überblick über die zur Verfügung stehenden Datensätze und eine Diskussion der Vor- und Nachteile der einzelnen Datensätze gibt Anhang A. Die vorliegende Arbeit versucht diese Lücke mit dem SAVE Datensatz weiter zu schließen. Die SAVE Befragung ermöglicht es, eine Vorsorgefähigkeits-, Vorsorgebereitschafts- wie auch eine Vorsorgeniveauanalyse von Selbständigen und abhängig Beschäftigten durchzuführen.

\section{Der SAVE Datensatz}

Das Mannheimer Forschungsinstitut Ökonomie und demographischer Wandel (MEA) führt seit 2001 zusammen mit TNS-Infratest die SAVE Befragung durch. Ein Schwerpunkt liegt auf dem Sparverhalten und der Vermögensbildung deutscher Haushalte. Zusammen mit detaillierten Fragen über soziodemographische Merkmale und Einkommen liegt eine weitere Besonderheit des

\footnotetext{
${ }^{5}$ Unter direkten Altersvorsorgemaßnahmen versteht man die erwobenen Ansprüche in der ersten, zweiten und dritten Säule der Altersvorsorge. Unter den indirekten Maßnahmen wird das Nettogesamtvermögen ohne die drei Säulen der Altersvorsorge verstanden.

${ }^{6}$ Weitere Literatur, die sich mit dem Thema beschäftigt ist Dräther, Fachinger und Oelschläger (2001). Sie analysieren die Mikrozensen von 1991 bis 1996, um verschiedene Gruppen von selbständig Tätigen mit und ohne obligatorischem Altersversicherungssystem zu identifizieren. Wie die Autoren selbst deutlich machen, sind die Ergebnisse nicht zufriedenstellend, da es zu großen Abweichungen zwischen Geschäftsstatistiken und den Ergebnissen kommt.

Ein weiterer Aspekt wird durch die Studie „Altersvorsorge in Deutschland 2005“ (AVID 2005) von Heien, Kortmann und Schatz (2007, S. 248 ff) aufgezeigt. Sie finden heraus, dass die Erwerbsbiographien von Individuen im untersten Nettoeinkommensquintil zwei- bis dreimal längere Phasen der Selbständigkeit aufweisen als Individuen in den anderen 4 Quintilen. Dieser Effekt ist auch für Ostdeutschland leicht abgeschwächt zu beobachten.
} 
Datensatzes in der Erfassung von Erwartungen, Haltungen und Einstellungen sowie der Gesundheit der Befragten. Von 2005 an erreichte die SAVE Umfrage ein relativ stabiles Panel, mit dem kleinsten Stichprobenumfang von 2305 befragten Haushalten in 2005 und dem größten Stichprobenumfang von 3474 befragten Haushalten in 2006 (Börsch-Supan et al., 2008). Daher wird das SAVE Panel ab 2005 bis 2008 für diese Untersuchung herangezogen. Trotz des relativ geringen Stichprobenumfangs sind die Stichprobeneigenschaften in Bezug auf die Selbständigenpopulation der SAVE Studie gut. Vergleicht man verschiedene soziodemographische Merkmale von SAVE 2005 und 2006 mit den zur Verfügung stehenden Scientific Use-files des Mikrozensus aus 2005 und 2006 und zusätzlich mit der EVS aus 2003 (ungewichtet), so ist festzustellen, dass SAVE trotz der geringen Stichprobengröße gute Stichprobeneigenschaften im Abgleich mit dem Mikrozensus aufweist (Anhang B).

SAVE ermöglicht es, eine Vorsorgefähigkeits- wie auch eine Vorsorgebereitschaftsanalyse durchzuführen. Ferner sind indirekte Altersvorsorgemaßnahmen komplett abdeckt. Auch bei der direkten Altersvorsorge liegen detaillierte Informationen über die Vermögenshöhe in der zweiten und dritten Säule vor, wohingegen erworbene Anwartschaften in der ersten Säule nur als ja/nein Fragen erhoben werden. Soloselbständige sind hingegen nicht identifizierbar. Schaubild 1 zeigt die Erfragung des Berufsstandes im SAVE Fragebogen von 2005 bis 2008. Diese Frage bildet die Ausgangsbasis zur Konstruktion der nicht obligatorisch abgesicherten Selbständigenpopulation in der vorliegenden Untersuchung. Die Rate von Fehlwerten im Datensatz bzgl. des Berufsstandes ist sehr gering und liegt über die Jahre 2005 bis 2008 bei durchschnittlich 3,1\%. ${ }^{7}$

\section{Schaubild 1: Frage nach dem Berufsstand aus dem SAVE Fragebogen 2008}

19. Sind Sie und ist Ihr(e) Partner(in) zurzeit...

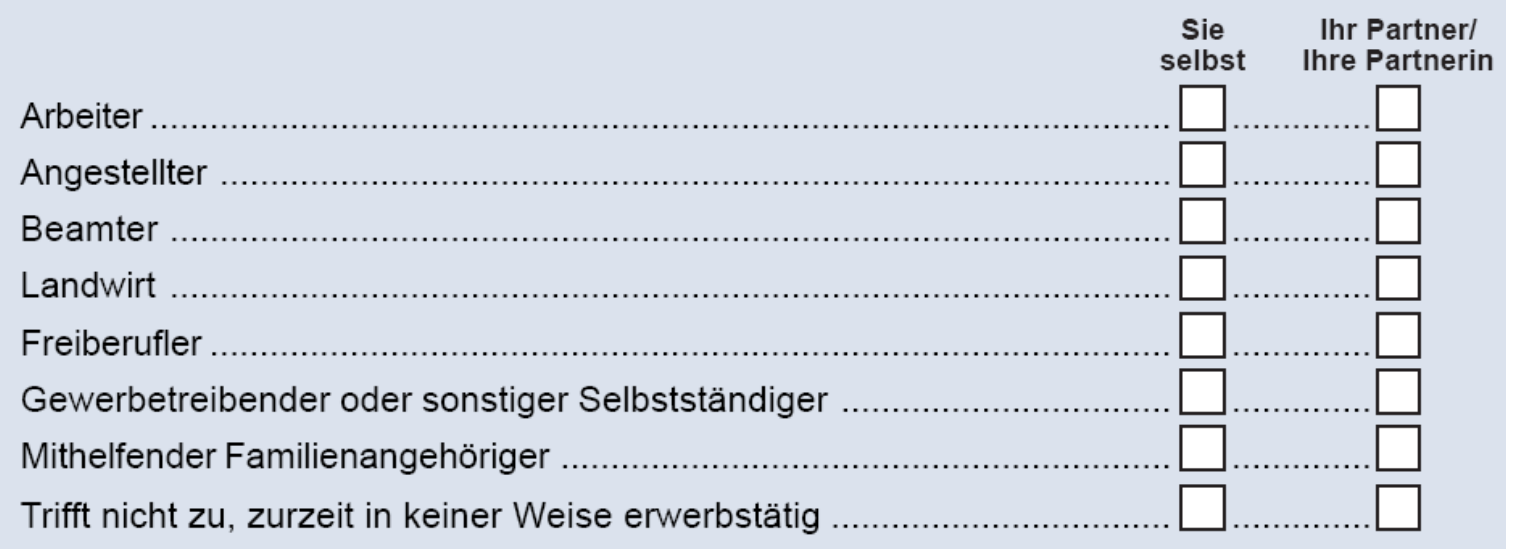

\footnotetext{
${ }^{7}$ Für die deskriptive Analyse wird nur der erste der fünf vollständig imputierten Datensätze untersucht (Schunk, 2008; Ziegelmeyer, 2009a).
} 
Da das Anliegen dieser Studie vor allem die Evaluation der Situation nicht obligatorisch abgesicherter Selbständiger in Bezug auf ihr Altersvorsorge-Verhalten ist, wurden die Kategorien „Freiberufler“, „Gewerbetreibender oder sonstiger Selbständiger“ und „mithelfender Familienangehöriger“ zu einer - im Folgenden nur als „Selbständige“ bezeichneten - Gruppe zusammengefasst. ${ }^{8}$ Landwirte wurden bewusst herausgelassen, da diese, obwohl selbständig, in der Alterssicherung der Landwirte als Teil der GRV ab einer gewissen Mindestgröße des Unternehmens pflichtversichert sind (Fachinger/Oelschläger/Schmähl, 2004, S. 36/37, Fußnote 73). Die Gruppe der mithelfenden Familienangehörigen wurde, obwohl nicht selbständig, dieser Gruppe hinzugefügt, da diese nicht der Sozialversicherungspflicht unterliegen, wenn ihnen kein oder kein regelmäßiges Arbeitsentgelt gezahlt wird, und daher ebenfalls die verstärkte Gefahr einer nicht ausreichenden Alterssicherung vorliegt. ${ }^{9}$ Von den 857.000 Selbständigen, die in den Freien Berufen in 2005 beschäftigt waren (IFB, 2005), waren etwa 335.375, d.h. ca. 39\% (Kohlmeier, 2009, S. 22), in Berufsständischen Versorgungswerken versichert. Aus diesem Grund wurden aus der Kategorie Freiberufler all diejenigen ausgeschlossen, die angaben, voraussichtlich ein Alterseinkommen von einem Berufsständischen Versorgungswerk (BSV) zu beziehen. ${ }^{10}$ Auch in der Kategorie „Gewerbetreibender oder sonstiger Selbständiger“ besteht die Möglichkeit der Versicherung in der GRV. Laut der Statistik der Deutschen Rentenversicherung waren am Ende des Jahres 2006 insgesamt 368.297 Personen in der GRV pflichtversichert. Da die meisten selbständig Tätigen eine Anwartschaft in der GRV erwarten, ${ }^{11}$ wurde hier keine Beschränkung dieser Kategorie vorgenommen. ${ }^{12}$

Bei einigen Analysen ist ein Vergleich der nicht obligatorisch abgesicherten Selbständigen mit einer Vergleichsgruppe sinnvoll. Hierfür wurden die obligatorisch in der GRV versicherten Arbeiter und Angestellten zu ,,abhängig Beschäftigten“ zusammengefasst.

\footnotetext{
${ }^{8}$ In SAVE 2005 bis 2008 gibt es keine Frage, die es ermöglicht, obligatorisch und nicht obligatorisch abgesicherte Selbständige anhand einer eigenen Frage zu unterscheiden.

${ }^{9} \mathrm{Ob}$ ein abhängiges Beschäftigungsverhältnis bei mithelfenden Familienangehörigen besteht ist teilweise schwierig abzugrenzen. Das abhängige Beschäftigungsverhältnis ist seinerseits wieder notwendig um die Sozialversicherungspflicht zu begründen. Für weitere Informationen siehe „Übersicht über das Sozialrecht“ (2008, S. 110).

${ }^{10}$ Siehe Frage 81 in 2005, Frage 82 in 2006, Frage 87 in 2007 und Frage 86 in 2008. Die ausgeschlossene Gruppe hat auch ein signifikant höheres individuelles Nettoeinkommen, was für Freiberufler wie Rechtanwälte, Ärzte, Steuerberater usw. spricht, die in den jeweiligen berufsständischen Versorgungswerken abgesichert sind. So liegt das individuelle Nettoeinkommen im Median bei 27.000€ und somit um 12.646€ höher als bei Freiberuflern, die keine Anwartschaft aus der BSV erwarten. Der Mittelwert beim individuellen Nettoeinkommen der ausgeschlossenen Freiberufler liegt bei $29.470 €$ und ist 7.706€ größer als den in der Stichprobe verbleibenden Freiberuflern.

${ }^{11}$ Bei den Kategorien „Gewerbetreibender oder sonstiger Selbständiger“ und „Freiberufler“ sind es in 2006 auf individueller Ebene über 80\%, die eine Anwartschaft aus der GRV erwarten. Dieser hohe Prozentsatz kommt wahrscheinlich dadurch zustande, dass viele aktuell selbständig Tätige zu anderen Zeitpunkten in ihrer Erwerbshistorie abhängig beschäftigt waren.

12 Anhang C erörtert weitere Anmerkungen zur Stichprobe.
} 
Da sowohl das Einkommen, als auch die Ersparnis und das Vermögen retrospektiv für das letzte Jahr erfragt werden, muss beispielsweise der Berufsstand des Fragebogens 2006 mit dem Einkommen, der Ersparnis und dem Vermögen für 2006 aus dem Fragebogen 2007 gepaart werden. Dies führt allerdings dazu, dass die Stichprobengröße zurückgeht. Zum einen geht ein Jahr des Panels verloren, zum anderen muss der Befragte des aktuellen Jahres auch im Folgejahr befragt worden sein. Die linke Hälfte von Tabelle 1 gibt einen Überblick über die zur Verfügung stehenden Beobachtungen auf Individualebene.

\section{Tabelle 1: Anzahl der Beobachtungen von Selbständigen und abhängig Beschäftigten}

\begin{tabular}{c|cc|cc} 
& \multicolumn{2}{c}{ Individualebene } & \multicolumn{2}{c}{ Haushaltsebene } \\
Jahr & Selbständiger & abh. Beschäftigter & Selbständiger & abh. Beschäftigter \\
\hline \hline 2005 & 212 & 1284 & 100 & 658 \\
2006 & 302 & 2057 & 163 & 1011 \\
2007 & 269 & 1864 & 133 & 898 \\
\hline Total & $\mathbf{7 8 3}$ & $\mathbf{5 2 0 5}$ & $\mathbf{3 9 6}$ & $\mathbf{2 5 6 7}$
\end{tabular}

Quelle: SAVE 2005-2008. Imputierte Datensätze mit Nr. 1.

Jedoch ist der Blick auf das Individuum allein zu kurz gefasst, da er wichtige Ressourcen auf Haushaltsebene nicht berücksichtigt. Ferner liegen verschiedene Größen wie die Ersparnis oder das Vermögen im SAVE Datensatz nur auf Haushaltsebene vor. Aus diesem Grund muss auf Haushaltsebene definiert werden, wann ein Haushalt als selbständig bzw. abhängig beschäftigt angesehen wird. Ein Haushalt gilt dann als selbständig tätig, wenn mindestens 50\% des Einkommens aus selbständiger Tätigkeit erzielt werden. Ein Haushalt ist ein abhängig beschäftigter Haushalt, wenn mindestens $50 \%$ des Einkommens aus abhängiger Beschäftigung erwirtschaftet wird. ${ }^{13}$ Dies bedeutet, dass der Berufsstatus des Haupteinkommensbeziehers über den Berufsstatus für den Haushalt entscheidet. Tabelle 1 zeigt, wie viele Beobachtungen in der Gruppe der Selbständigen und abhängig Beschäftigten auf Individual- und Haushaltsebene über die Jahre enthalten sind.

\footnotetext{
${ }^{13}$ Da in SAVE eine genaue Aufschlüsselung des Einkommens in Einkommen aus abhängiger und/oder selbständiger Beschäftigung nicht vorliegt, wird das Einkommen der befragten Person oder des Partners nach der vorher eingeführten Klassifikation der Gruppe „Selbständiger“ und „abhängig Beschäftigter“ als Einkommen aus selbständiger bzw. abhängiger Beschäftigung bezeichnet. Da die befragte Person und deren Partner oftmals unterschiedlichen Berufsgruppen zugeordnet sind, entscheidet dann der in SAVE angegebene Einkommensanteil der befragten Person oder des Partners, ob ein Haushalt insgesamt als selbständiger oder abhängig beschäftigter Haushalts klassifiziert wird. Ist beispielsweise die befragte Person selbständig tätig und trägt $70 \%$ zum Nettoeinkommen bei, wird der Haushalt als selbständig klassifiziert. Verdient ein als abhängig beschäftigt arbeitender Partner in einem anderen Haushalt $85 \%$ des Nettoeinkommens, so gilt der Haushalt als abhängig beschäftigt. Bei Fällen, in denen sowohl $50 \%$ aus abhängiger als auch 50\% aus selbständiger Tätigkeit erzielt werden, d.h. ein Partner ist selbständig und einer abhängig beschäftigt, wobei beide gleich viel zum Nettoeinkommen beitragen, wurden diese Haushalte keiner der beiden Gruppen zugeordnet (53 Beobachtungen). Eine Festlegung auf mehr als 50\% des Gehalts wurde nicht getroffen, da die oftmalige Angabe einer 50:50 Aufteilung zum Verlust wertvoller Beobachtungen geführt hätte (43 (301) Beobachtungen weniger für selbständige (abhängig beschäftigte) Haushalte als in Tabelle 1).
} 


\section{Deskriptive Analysen}

\subsection{Vorsorgefähigkeit}

Der erste Schritt besteht in einer Analyse der Vorsorgefähigkeit. Dabei wird besonderes Augenmerk auf die Haushaltsebene gelegt, um die Ressourcen, die dem Partner zur Verfügung stehen, einzubeziehen. Vorsorgefähigkeit wird in diesem Falle anhand des aktuellen Nettoeinkommens gemessen, da üblicherweise aus dem Nettoeinkommen heraus gespart wird. ${ }^{14}$ Problematisch ist, dass nicht bekannt ist, inwieweit Selbständige Aufwendungen zu ihrer sozialen Sicherung bereits bei der Angabe ihrer Nettoeinkommen berücksichtigen. Eine bessere Evaluation der Vorsorgefähigkeit wäre mit dem „permanenten“ Einkommen möglich. Das SAVE Panel eröffnet die Möglichkeit, zumindest das Durchschnittseinkommen über mehrere Jahre zu berechnen. Je mehr Jahre einbezogen werden können, desto mehr nähert sich das Durchschnittseinkommen dem ,permanenten“ Einkommen an. Jedoch setzen die vier Jahre des unbalancierten SAVE Panels und die eingeschränkte Stichprobengröße bestimmte Grenzen. Selbst die Konstruktion von „permanentem“ Einkommen aus dem Querschnitt durch die von King und Dicks-Mireaux (1982) eingeführte Methode hat schwerwiegende Nachteile wie von Ziegelmeyer (2009b) beschrieben und kommt daher nicht zur Anwendung. Abbildung 1 und Tabelle 2 zeigen verschiedene Statistiken zum durchschnittlichen Monatsnettoeinkommen.

Auch wenn das Nettoeinkommen von Selbständigen und abhängig Beschäftigten nur eingeschränkt miteinander vergleichbar ist, weil vom Nettoeinkommen der abhängig Beschäftigten bereits Steuern und Sozialversicherungsbeiträge (Arbeitnehmer und Arbeitgeber) abgezogen wurden und bei nicht obligatorisch abgesicherten Selbständigen nur die Steuern, hilft ein Vergleich die später ermittelten Ergebnisse zur Vorsorgefähigkeit von Selbständigen zu erklären. Anhand von vier verschiedenen Einkommensdefinitionen wird der Vergleich durchgeführt:

a) Monatsnettoeinkommen auf individueller Ebene in $2006 .{ }^{15}$

b) Monatliches Nettoäquivalenzeinkommen auf individueller Ebene in $2006 .{ }^{16}$

c) Monatliches Nettoäquivalenzeinkommen in 2006. Der Berufsstand des Haupteinkommensbeziehers entscheidet über den Berufsstand des Haushaltes.

d) Äquivalenzgewichtetes Nettodurchschnittseinkommen über die Jahre 2005 bis 2007. Dabei musste ein Haushalt mindestens 2 Jahre beobachtet werden. ${ }^{17}$

\footnotetext{
${ }^{14}$ In manchen Fällen wird auch aus dem Bruttoeinkommen gespart. Ein Beispiel dafür ist die Entgeltumwandlung für die betriebliche Altersvorsorge für abhängig Beschäftigte. Für Selbständige ist an dieser Stelle die Rürup-Rente zu nennen.

${ }^{15} 2006$ wurde zur Darstellung des aktuellen Nettoeinkommens ausgewählt, da es in der Mitte des Beobachtungszeitraumes von 2005 bis 2007 liegt und die größte Stichprobengröße aufweist (Tabelle 1).

${ }^{16}$ Das Haushaltsnettoeinkommen wird mit der Quadratwurzel der im Haushalt lebenden Personen skaliert. Diese Äquivalenzskalierung findet sich in neueren OECD Publikationen wieder (OECD, 2005).
} 


\section{Abbildung 1: Vergleich des durchschnittlichen Monatsnettoeinkommens in 2006}

a)

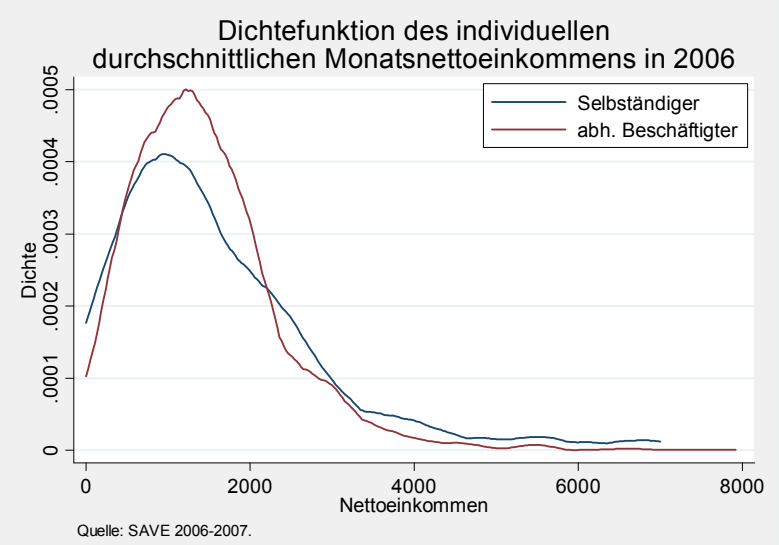

c)

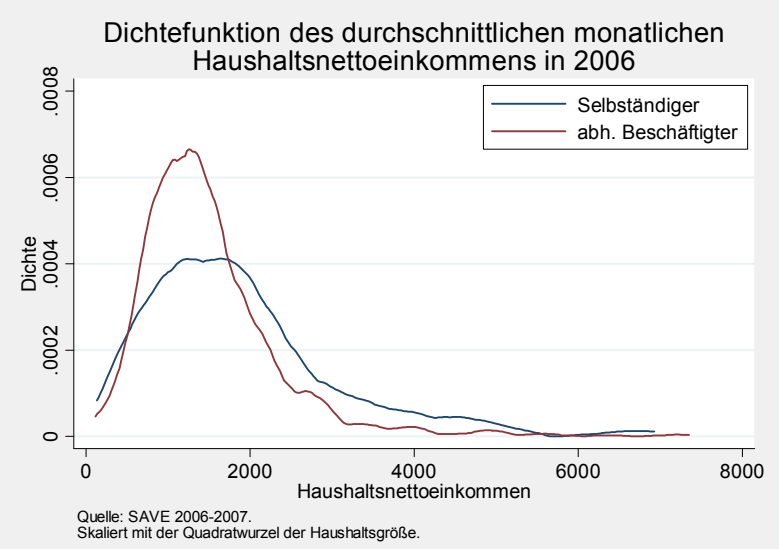

b)

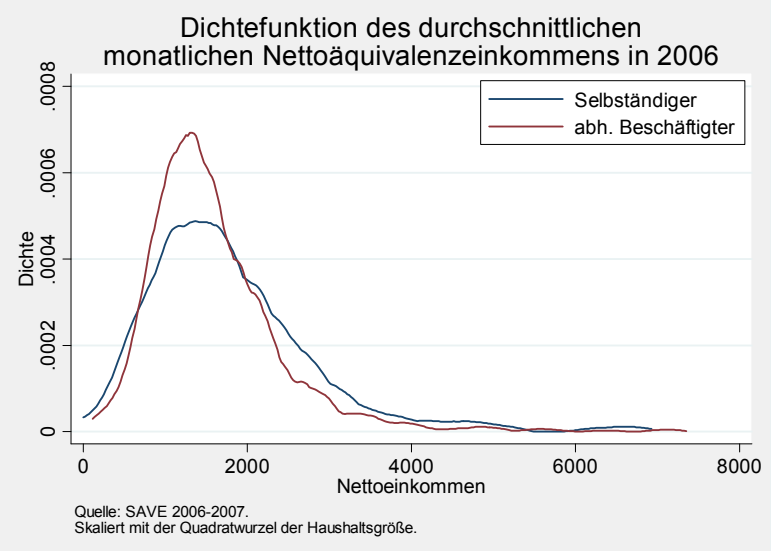

d)

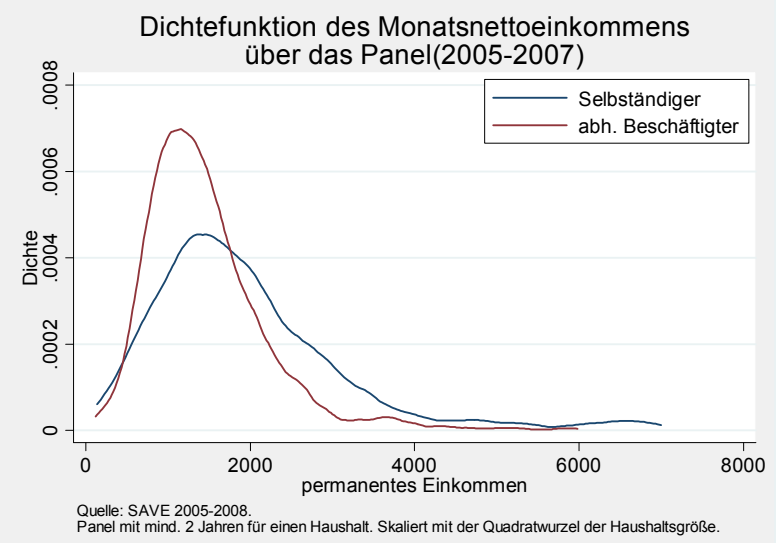

In Abbildung 1 sind für die vier Einkommensdefinitionen die Dichtefunktionen dargestellt. Zuerst fällt auf, dass Selbständige am linken Ende der Verteilung eine höhere Dichte aufweisen und dies, obwohl keine Beiträge zur Sozialversicherung abgeführt wurden. Gerade der linke Bereich der Verteilung ist für die Beurteilung der Vorsorgefähigkeit entscheidend. Der Mittelwert des Monatsnettoeinkommens ist für Selbständige aber größer (Tabelle 2), was an der höheren Dichte von Beobachtungen am oberen Ende der Verteilung liegt. In Bezug auf Definition a) bis c) finden sich diese Ergebnisse auch für die Jahre 2005 und 2007 wieder, wobei in 2005 unter Einbezug des Haushaltes die Verteilungen von Selbständigen und abhängig Beschäftigten am unteren Ende enger beieinander liegen. Die Ergebnisse werden durch die bei Kohlmeier (2009, S. 112-114) durchgeführte Betrachtung des Bruttoeinkommens von Selbständigen und abhängig Beschäftigten in der EVS 2003 bestätigt. Sie stellt fest, dass es im Vergleich zu den abhängig Beschäftigten relativ mehr Selbstständige mit einem Bruttoeinkommen unter 1.100€ und über 4.500€ gibt.

\footnotetext{
${ }^{17}$ Zur Einteilung der Haushalte in selbständige und abhängig beschäftigte findet die gleiche Definition Anwendung wie auf Seite 9. Nur das hier nicht das Einkommen aus einem Jahr zugrunde liegt, sondern aus allen verfügbaren Jahren. Eine Beschränkung der Stichprobe auf Haushalte, die in allen 3 Jahren beobachtet wurden, wurde wegen der geringen Stichprobengröße nicht vorgenommen.
} 
Tabelle 2: Vergleich des durchschnittlichen Monatsnettoeinkommens

\begin{tabular}{|c|c|c|c|c|c|c|}
\hline & $\mathbf{N}$ & Mittelwert & p10 & p25 & p50 & p75 \\
\hline \multicolumn{7}{|c|}{ a) Einkommen in 2006 auf Individualebene } \\
\hline abh. Beschäftigter & 2057 & 1467 & 450 & 800 & 1320 & 1900 \\
\hline Selbständiger & 302 & 1764 & 300 & 750 & 1255 & 2216 \\
\hline \multicolumn{7}{|c|}{ b) Einkommen in 2006 auf Individualebene unter Einbezug des Haushaltes } \\
\hline abh. Beschäftigter & 2057 & 1599 & 800 & 1061 & 1443 & 1925 \\
\hline Selbständiger & 302 & 1927 & 750 & 1118 & 1533 & 2252 \\
\hline \multicolumn{7}{|c|}{ c) Einkommen in 2006 auf Haushaltsebene } \\
\hline abh. Beschäftigter & 1011 & 1511 & 700 & 970 & 1342 & 1789 \\
\hline Selbständiger & 163 & 2048 & 707 & 1000 & 1732 & 2350 \\
\hline \multicolumn{7}{|c|}{ d) Einkommen über mind. 2 Jahre auf Haushaltsebene } \\
\hline abh. Beschäftigter & 883 & 1457 & 731 & 963 & 1312 & 1762 \\
\hline Selbständiger & 120 & 2112 & 779 & 1179 & 1700 & 2462 \\
\hline
\end{tabular}

Quelle: Eigene Berechnung. SAVE 2005-2008. Imputierter Datensatz mit Nr. 1.

Im Folgenden werden anhand verschiedener Kriterien diejenigen Selbständigen identifiziert, die aus ihrem aktuellen Nettoeinkommen nicht ,adäquat“ für das Alter vorsorgen können. ${ }^{18}$ Eine adäquate Vorsorge ist nach der hier gewählten Definition dann möglich, wenn das Nettoeinkommen eine bestimmte Grenze überschreitet.

- Eine Grenze bildet die absolute Armutsgrenze oder das soziokulturelle Existenzminimum, welches auf den tatsächlichen Verbrauchsausgaben basiert (absolute Armut). ${ }^{19}$ Für die Jahre 2005-2007 beträgt das im fünften Existenzminimumbericht (2004) angegebene sächliche Existenzminimum 613€ pro Monat für einen Alleinstehenden. Das im sechsten Existenzminimumsbereicht festgelegte neue sächliche Existenzminimum gilt erst ab dem Jahr 2008.

- Eine andere Grenze ist die relative Armutsgrenze, die beispielsweise im dritten Armutsund Reichtumsbericht der Bundesregierung (2008) 60\% des mittleren Nettoäquivalenzeinkommens entspricht (relative Armut). Für diese Untersuchung wird das Medianeinkommen in Bezug auf die Stichprobe des jeweiligen Jahres berechnet und beschränkt sich nicht nur auf Selbständige und abhängig Beschäftigte. Die relative Armutsgrenze entspricht $60 \%$ des Medianeinkommens.

\footnotetext{
${ }^{18}$ Dabei ist es schwer und zu einem gewissen Umfang arbiträr eine „adäquate“ Ersparnis für die Altersvorsorge zu definieren (Banks, 2005, Kapitel 6). Es ist allerdings von Bedeutung ,adäquat“ von ökonomisch „optimal“ zu unterscheiden. So lösen unter anderem Scholz, Seshadri und Khitatrakun (2006) ein Konsummaximierungsproblem über den Lebenszyklus, um „optimale“ Konsum- und somit Sparentscheidungen abzuleiten.

${ }^{19}$ Für verschiedene Möglichkeiten Armut zu definieren siehe Breyer/Buchholz (2007, S. 46 ff).
} 
Fällt das Nettoeinkommen eines Individuums (Haushaltes) unter die relative/absolute Armutsgrenze, wird davon ausgegangen, dass das Nettoeinkommen des Individuums (Haushaltes) vollständig konsumiert wird. Jeder Euro des Nettoeinkommens, der über dieser Grenze liegt, wird per Annahme gespart. Dahinter steht die Idee, dass das Individuum zuerst in der Lage sein muss, seine Grundbedürfnisse zu stillen. Der Teil des Einkommens, der dann noch verbleibt, stünde zur Vorsorge für das Alter zur Verfügung. Doch welcher Betrag muss gespart werden, um das Individuum vor Altersarmut zu schützen? Definiert man den von der Grundsicherung im Alter zur Verfügung gestellten Betrag ${ }^{20}$ als ausreichend zum Schutz vor Altersarmut, so muss das Individuum soviel von seinem Einkommen mindestens sparen, dass am Ende des Erwerbslebens genügend Vermögen vorhanden ist, um eine Annuität in der Höhe der Grundsicherung sicherzustellen. Anhang D geht auf die Berechnung eines solchen minimal nötigen Sparbetrages und die erforderlichen Annahmen ein. Dieser minimale Sparbetrag wird auf die relative/ absolute Armutsgrenze addiert, um somit das minimale Einkommen zu erhalten, ab welchem eine ausreichende Sparfähigkeit vorliegt, die zumindest die Grundsicherung im Alter gewährleisten kann.

Tabelle 3 gibt eine Übersicht über die relativen und absoluten Armutsgrenzen mit und ohne den minimal nötigen Sparbetrag über die Jahre 2005-2007 für die Bezugsebenen a), b), c) und d) die bereits in Abbildung 1 und Tabelle 2 zur Anwendung gekommen sind. Kern der Tabelle 3 sind die Angaben über den Anteil der Selbständigen, die nicht in der Lage sind das nötige monatliche Nettoeinkommen aufzubringen, damit eine adäquate Vorsorgefähigkeit vorliegt.

Die anschließend diskutierten Ergebnisse beziehen sich auf die Durchschnittswerte über die Jahre 2005-2007. In diesem Zeitraum liegen die individuellen Nettoeinkommen von etwa $27 \%$ aller Selbständigen unter der relativen Armutsgrenze. Dieser Anteil reduziert sich auf 14-15\%, wenn man das äquivalenzgewichtete Einkommen auf Haushaltsebene betrachtet. Addiert man zur relativen Armutsgrenze noch die minimal nötige Ersparnis, dann erhöht sich der Anteil nochmals um etwa 6-7 Prozentpunkte. Nimmt man die absolute Armut als Rechengrundlage, ist der Unterschied zur relativen Armutsgrenze auf individueller Ebene am geringsten. Mit 24\% der Selbständigen auf individueller Ebene unter der absoluten Armutsgrenze liegt man hier etwa 3\% unter dem Wert der relativen Armutsgrenze. Diese Differenz erhöht sich auf nahezu 10\%, wenn man das äquivalenzgewichtete Nettoeinkommen in Bezug auf Armutsgrenze mit Sparbetrag auswertet. Hier reduziert

\footnotetext{
${ }^{20}$ Die Grundsicherung im Alter setzt sich aus verschiedenen Leistungen zusammen und kann daher nach der derzeitigen Gesetzeslage variieren. So kommen zum maßgebenden Regelsatz nach dem SGB XII in erster Linie die angemessenen tatsächlichen Aufwendungen für Unterkunft und Heizung hinzu. Aus diesem Grund wird die in der Beispielrechnung ausgewiesene Grundsicherungsleistung vor Einkommensberücksichtigung auf der Homepage der Deutschen Rentenversicherung in Höhe von $647 €$ im Jahr 2007/2008 für den Befragten als Rechnungsgrundlage genommen.
} 
sich der Anteil von 21-22\% der Selbständigen unter der relativen Armutsgrenze mit Sparbetrag auf etwa 11-12\% unter der absoluten Armutsgrenze mit Sparbetrag. Dies zeigt auf, wie stark die Ergebnisse mit der Definition eines adäquaten Nettoeinkommens zur Altersvorsorge schwanken können.

Tabelle 3: Vorsorgefähigkeit (2005-2007) von Selbständigen auf Basis des monatlichen Nettoeinkommens

\begin{tabular}{|c|c|c|c|c|c|c|c|c|}
\hline \multirow[b]{2}{*}{ a) Individualebene } & \multicolumn{4}{|c|}{ relative Armut } & \multicolumn{4}{|c|}{ absolute Armut } \\
\hline & 2005-2007 & 2005 & 2006 & 2007 & 2005-2007 & 2005 & 2006 & 2007 \\
\hline Median & & 1190 & 1200 & 1170 & & & & \\
\hline Armutsgrenze & & 714 & 720 & 702 & & 613 & 613 & 613 \\
\hline+ min. Ersparnis & & 831 & 838 & 823 & & 730 & 731 & 734 \\
\hline \multicolumn{9}{|c|}{ Wie viele Selbständige haben ein individuelles Nettoeinkommen, dass nicht größer ist als } \\
\hline Armutsgrenze & $27,2 \%$ & $25,0 \%$ & $24,2 \%$ & $32,3 \%$ & $24,0 \%$ & $22,2 \%$ & $21,9 \%$ & $27,9 \%$ \\
\hline Armutsgrenze + min Ersparnis & $33,3 \%$ & $33,5 \%$ & $29,5 \%$ & $37,5 \%$ & $28,9 \%$ & $27,4 \%$ & $24,5 \%$ & $34,9 \%$ \\
\hline \multicolumn{9}{|c|}{ b) Individualebene unter Einbezug des Haushaltes } \\
\hline Median & & 1328 & 1414 & 1414 & & & & \\
\hline Armutsgrenze & & 797 & 849 & 849 & & 613 & 613 & 613 \\
\hline+ min. Ersparnis & & 913 & 966 & 970 & & 730 & 731 & 734 \\
\hline \multicolumn{9}{|c|}{ Wie viele individuell Selbständige, haben kein äquivalenzgewichtetes Haushaltsnettoeinkommen, dass größer ist als } \\
\hline Armutsgrenze & $14,3 \%$ & $12,3 \%$ & $13,9 \%$ & $16,4 \%$ & $6,5 \%$ & $6,1 \%$ & $5,6 \%$ & $7,8 \%$ \\
\hline Armutsgrenze + min Ersparnis & $20,7 \%$ & $17,5 \%$ & $21,2 \%$ & $22,7 \%$ & $11,4 \%$ & $10,8 \%$ & $10,6 \%$ & $12,6 \%$ \\
\hline \multicolumn{9}{|l|}{ c) Haushaltsebene } \\
\hline Median & & 1255 & 1386 & 1392 & & & & \\
\hline Armutsgrenze & & 753 & 831 & 835 & & 613 & 613 & 613 \\
\hline+ min. Ersparnis & & 871 & 951 & 959 & & 731 & 733 & 737 \\
\hline
\end{tabular}

Wie viele "selbständige" Haushalte haben ein äquivalenzgewichtetes Haushaltsnettoeinkommen, dass nicht größer ist als

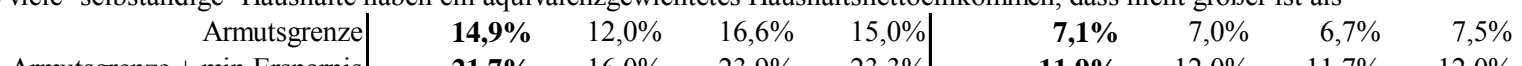

d) Haushaltsebene (Betrachtung über mind. 2 Jahre)

\begin{tabular}{l|r|l}
\hline Median & 1363 & 613 \\
Armutsgrenze & 818 & 731 \\
$\quad+$ min. Ersparnis & 936 &
\end{tabular}

Wie viele "selbständige" Haushalte haben ein äquivalenzgewichtetes Haushaltsnettoeinkommen, dass nicht größer ist als

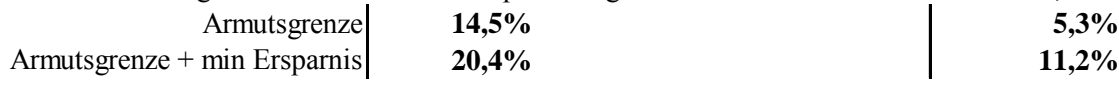

Quelle: Eigene Berechnung. SAVE 2005-2008. Imputierter Datensatz mit Nr. 1.

Das Medianeinkommen beschränkt sich nicht nur auf abhängig Beschäftigte und Selbständige, sondern bezieht alle anderen Gruppen mit ein.

Der Analyse folgend ist zu betonen, wie wichtig es ist, die Ressourcen eines Haushaltes als Ganzes zu betrachten. Der Einbezug des äquivalenzgewichteten Nettoeinkommens des gesamten Haushaltes führt zu einer Reduktion der nichtvorsorgefähigen Selbständigen von etwa 12\% für das relative Armutsmaß und gar 17\% für das absolute Armutsmaß. Mit 11-12\% für die absolute Armutsgrenze mit Ersparnis und 21-22\% für die relative Armutsgrenze mit Ersparnis bleibt der Anteil Selbständiger, die selbst auf Haushaltsebene keine ausreichende Vorsorgefähigkeit aufwei- 
sen, auf hohen Niveau. Die Unterschiede zwischen den Ergebnissen in Bezug auf die relative und die absolute Armutsdefinition kommt durch die unterschiedliche Höhe der Grenzen zustande. Unter die relative Armutsgrenze fallen mehr Haushalte, da durch sie ein höherer Konsum zugebilligt wird.

\subsection{Vorsorgebereitschaft}

Der zweite Schritt in der Analyse beleuchtet die Bereitschaft der Individuen vorzusorgen. Diese Vorsorgebereitschaft wird anhand der Jahresersparnis gemessen ${ }^{21}$ und folgt der Frage, in welchem Umfang Selbständige mehr sparen als abhängig Beschäftigte. Verschiedene deskriptive Statistiken tragen zu einer ersten Beantwortung der Frage bei. Ebenso wie das Nettoeinkommen ist die Jahresersparnis eine Momentaufnahme. Dennoch kann eine auf den Jahreszeitraum beschränkte Betrachtung wichtige Anhaltspunkte über das Sparverhalten der Selbständigen liefern.

\section{Abbildung 2: Kumulative Häufigkeitsverteilung der jährlichen Ersparnis (2005-2007)}

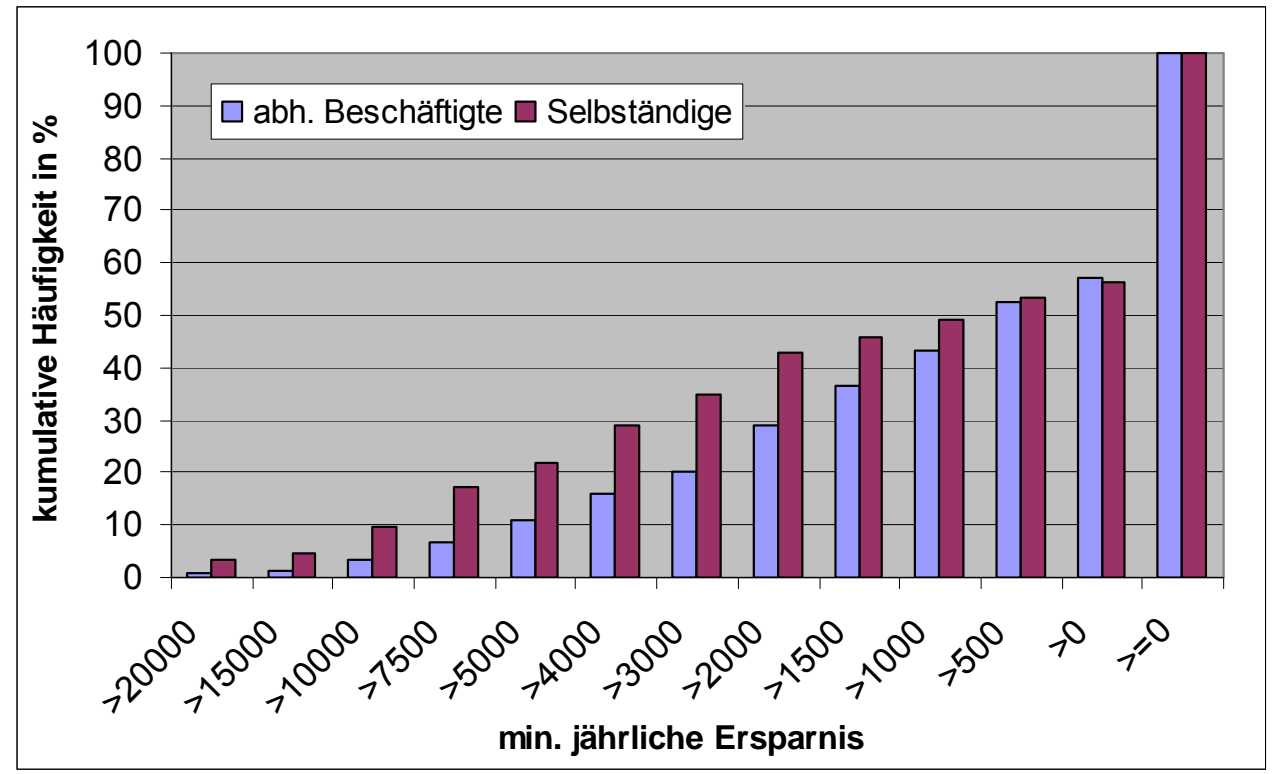

Abbildung 2 zeigt die kumulative Häufigkeitsverteilung der jährlichen Ersparnis im Beobachtungszeitraum von 2005-2007. Es fällt auf, dass etwa 43-44\% der abhängig Beschäftigten und der Selbständigen auf jährlicher Basis nicht sparen oder gar entsparen. Vor allem bei Sparbeträgen von $1.000 €$ bis $10.000 €$ finden sich mehr Selbständige, die mindestens diesen Betrag sparen. So sparen beispielsweise etwa 16\% der abhängig Beschäftigten mehr als $4.000 € \mathrm{im}$ Jahr, wohingegen etwa $29 \%$ der Selbständigen mehr als $4.000 €$ sparen.

${ }^{21}$ Die Frage in SAVE lautet: „Könnten Sie uns angeben, wie viel Geld Sie und Ihr(e) Partner(in) zusammen im „Vorjahr“ insgesamt gespart haben?“ Dabei werden durch die Antwortkategorie „Trifft nicht zu, habe im „Vorjahr" nichts angespart bzw. Ersparnisse aufgelöst" keine negativen Ersparnisse zugelassen. Dabei ist allerdings fraglich, ob Selbständige Investitionen in ihr Betriebsvermögen mit berücksichtigen. 


\section{Sparquoten über alle Einkommensgruppen}

Der Bezug zum Einkommen wird durch die Sparquote darstellbar. Dabei wird ein weiterer Einkommensbegriff verwendet, der außergewöhnliche Einkünfte mit einbezieht. ${ }^{22}$ Die Sparquote an sich kann auf verschiedene Weise errechnet werden. Ein Weg ist die Sparquoten auf individueller Ebene zu berechnen und dann den Mittelwert oder den Median dieser individuellen Sparquoten für die jeweilige Gruppe darzustellen. Dies sind die beiden ersten in Tabelle 4 gezeigten Sparquoten. Eine weitere Möglichkeit ist die Aufsummierung der Jahresersparnis der jeweiligen Gruppe, die wiederum durch das aufsummierte Jahreseinkommen geteilt wird. Letztes wird in Tabelle 4 als „Sparquote über Durchschnitte“ bezeichnet.

Tabelle 4: Haushaltssparquoten über Berufsgruppen (2005-2007)

\begin{tabular}{|c|c|c|c|c|}
\hline & 2005 & 2006 & 2007 & 2005-2007 \\
\hline \multicolumn{5}{|c|}{ individuelle Durchschnittssparquoten } \\
\hline \multirow[t]{2}{*}{ abh. Beschäftigte } & $7,2 \%$ & $6,5 \%$ & $6,7 \%$ & $6,8 \%$ \\
\hline & $* *$ & $* *$ & $* *$ & *** \\
\hline Selbständige & $10,7 \%$ & $8,5 \%$ & $9,7 \%$ & $9,5 \%$ \\
\hline \multicolumn{5}{|c|}{ individuelle Mediansparquoten } \\
\hline abh. Beschäftigte & $3,2 \%$ & $3,5 \%$ & $2,8 \%$ & $3,2 \%$ \\
\hline Selbständige & $5,0 \%$ & $2,8 \%$ & $3,6 \%$ & $3,8 \%$ \\
\hline \multicolumn{5}{|c|}{ Sparquote über Durchschnitte } \\
\hline abh. Beschäftigte & $8,1 \%$ & $6,9 \%$ & $7,5 \%$ & $7,4 \%$ \\
\hline Selbständige & $11,5 \%$ & $6,4 \%$ & $9,8 \%$ & $8,2 \%$ \\
\hline
\end{tabular}

Quelle: Eigene Berechnung. SAVE 2005-2008. Imputierte Datensätze mit Nr. 1.

Einkommen mit außergewöhnlichen Einkünften.

ttest $\mathrm{H}_{0}: \mathrm{MW}_{\mathrm{B}}<\mathrm{MW}_{\mathrm{S}} ; *$ : $10 \%$ Signifikanzlevel; ** : $5 \%$; ***: $1 \%$.

Betrachtet man die Durchschnittswerte über 2005-2007 sparen Selbständige in Bezug auf die individuellen Durchschnittssparquoten mit 9,5\% mehr als die abhängig Beschäftigten mit 6,8\%. Der Unterschied von 2,7 Prozentpunkten ist signifikant zum 1\%-Niveau. Bei der individuellen Mediansparquote reduziert sich die Differenz auf 0,6 Prozentpunkte. Die Mediansparquote von 3,8\% für die Selbständigen zeigt durch den Vergleich zum Mittelwert eine linksschiefe Verteilung an. Die Sparquote über Durchschnitte für die Selbständigen liegt bei $8,2 \%$ und bei 7,4\% für die abhängig Beschäftigten. Die Sparquoten für beide Gruppen mögen auf den ersten Blick niedrig erscheinen. Dies liegt daran, dass das Einkommen im Nenner außergewöhnliche Einkünfte mit einbezieht. Tabelle 14 im Anhang E zeigt daher die Berechnung der Sparquoten ohne Berücksichti-

\footnotetext{
${ }^{22}$ Das hier verwendete Einkommen errechnet sich aus dem mit 12 multiplizierten durchschnittlichen Monatsnettoeinkommen und addiert außergewöhnliche Einkünfte wie Erbschaften eines Geld- oder Kapitalbetrages, Schenkungen, Lotteriegewinne, einmalige Gewinnausschüttungen, Vermögensausgleich im Scheidungsfall, Einkommenssteuerrückzahlung und sonstige einmalige Geld- oder Kapitaleinkünfte.
} 
gung von außergewöhnlichen Einkünften. Die Sparquoten steigen in diesem Fall nicht nur an, auch die Differenz zwischen Selbständigen und abhängig Beschäftigten wird größer. Der Grund dafür liegt in der Tatsache begründet, dass Selbständige im Schnitt höhere außergewöhnliche Einkünfte aufweisen als abhängig Beschäftigte.

Bisher war die Betrachtung auf Jahresbasis beschränkt. Eine Betrachtung über mehrere Jahre ist unter Ausnutzung des Panels möglich. Tabelle 5 zeigt verschiedene Sparquoten für abhängig Beschäftigte und Selbständige, von denen für erstere Betrachtung mindestens 2 Jahre an Beobachtungen vorhanden sind und für letztere Betrachtung alle 3 Jahre. Mehrere interessante Beobachtungen können dabei gemacht werden. Während sich die Sparquoten über die Durchschnitte der jährlichen Betrachtung in Tabelle 4 durch die Stichprobenbegrenzung bei den Panelsparquoten von $8,2 \%$ auf 6,8\% reduziert, steigt im Gegensatz dazu die Mediansparquote von 3,8\% über 6,4\% auf 7,2\% für die Selbständigen an. Für die abhängig Beschäftigten fällt der Anstieg auf lediglich $4,3 \%$ bei den Beobachtungen über alle drei Jahre weniger stark aus. Dies bedeutet, dass Haushalte, die in einem Jahr nichts oder nur sehr wenig sparen, in einem anderen Jahr mehr sparen. Ein solches Verhalten kann optimal sein und sich aus Anschaffungen dauerhafter Konsumgüter sowie Einkommensschwankungen ergeben. Auch reduziert sich die Anzahl der Haushalte, die nicht sparen bzw. entsparen von 44\% der Selbständigen auf jährlicher Basis auf nur noch 15,2\% in dem betrachteten Dreijahreszeitraum. Bei abhängig Beschäftigten reduziert sich der Anteil von etwa $43 \%$ auf 20\%. An dieser Stelle besteht jedoch auch die Problematik eines Selektionsprozesses, der darauf beruht, dass nur die erfolgreichen Selbständigen ,überleben“ und daher vermehrt über einen Zeitraum von 3 Jahren als Selbständige identifiziert werden.

Tabelle 5: Haushaltssparquoten im Panel (2005-2007)

\begin{tabular}{|c|c|c|c|c|c|}
\hline & Obs & $\begin{array}{c}\text { individuelle } \\
\text { DurchschnittsSQ }\end{array}$ & $\begin{array}{c}\text { individuelle } \\
\text { MedianSQ }\end{array}$ & $\begin{array}{c}\text { SQ über } \\
\text { Durchschnitte }\end{array}$ & $\begin{array}{c}\text { Ersparnis } \\
\quad<=0\end{array}$ \\
\hline mind. 2 Jahre & \multicolumn{5}{|c|}{$* * *$} \\
\hline $\begin{array}{l}\text { abh. Beschäftigte } \\
\text { Selbständige }\end{array}$ & $\begin{array}{l}883 \\
120\end{array}$ & $\begin{array}{l}6,7 \% \\
9,0 \%\end{array}$ & $\begin{array}{l}4,0 \% \\
6,4 \%\end{array}$ & $\begin{array}{l}7,5 \% \\
7,5 \%\end{array}$ & $\begin{array}{l}24,7 \% \\
25,0 \%\end{array}$ \\
\hline 3 Jahre & \multicolumn{5}{|c|}{$\overline{* * *}$} \\
\hline $\begin{array}{l}\text { abh. Beschäftigte } \\
\text { Selbständige }\end{array}$ & $\begin{array}{c}501 \\
66\end{array}$ & $\begin{array}{c}7,0 \% \\
10,4 \%\end{array}$ & $\begin{array}{l}4,3 \% \\
7,2 \%\end{array}$ & $\begin{array}{l}7,8 \% \\
6,8 \%\end{array}$ & $\begin{array}{l}20,2 \% \\
15,2 \%\end{array}$ \\
\hline
\end{tabular}

Quelle: Eigene Berechnung. SAVE 2005-2008. Imputierte Datensätze mit Nr. 1.

Einkommen mit außergewöhnlichen Einkünften.

ttest $\mathrm{H}_{0}: \mathrm{MW}_{\mathrm{B}}<\mathrm{MW}_{\mathrm{S}} ; *: 10 \%$ Signifikanzlevel; ** : $5 \%$; ***: $1 \%$.

Zusammenfassend ist zu konstatieren, dass ein Großteil der Selbständigen im Durchschnitt mehr spart als die abhängig Beschäftigten, vernachlässigt man die „Quasi-Ersparnis“ der abhängig Be- 
schäftigten durch den Erwerb von GRV-Anwartschaften. Um eine Aussage darüber zu treffen, ob die zusätzliche Ersparnis der Selbständigen ausreicht, die nicht erworbenen Anwartschaften in einem obligatorischen Altersicherungssystem auszugleichen, sind Angaben über das sozialversicherungspflichtige Bruttoeinkommen nötig, die in SAVE leider nicht vorliegen. ${ }^{23}$

\section{Einkommensspezifische Sparquoten}

Doch welche Rolle spielt das Einkommen und wie verändert sich die Sparquote über verschiedene Einkommensklassen? Tabelle 6 trägt verschiedene Sparquoten über unterschiedliche Haushaltsnettoeinkommensklassen ab. Die Sparquoten werden wie in Tabelle 5 über mindestens 2 Jahre berechnet. Für abhängig Beschäftigte erstreckt sich die Spannweite der Mediansparquote von $2,1 \%$ für die Haushaltsnettoeinkommensklasse kleiner gleich $1.000 €$ bis $8,3 \%$ in der obersten Einkommensklasse von über 4.000€. Für die Selbständigen fällt die Spannweite der Mediansparquote von $0 \%$ bis $13,5 \%$ noch stärker aus. Eine ähnliche Entwicklung ist bei dem Mittelwert der Sparquote über die Einkommensklassen hinweg zu beobachten, auch wenn der Anstieg der Sparquoten über die Einkommensklassen nicht so kontinuierlich verläuft wie beim Median. Auch die Anzahl der Haushalte, die nicht sparen oder gar entsparen, reduziert sich bei den Selbständigen von $75 \%$ in der untersten Einkommensklasse auf $8 \%$ in der obersten Einkommensklasse. Es fällt auf, dass bis zu einem Haushaltsnettoeinkommen von $2.000 €$ die Selbständigen sowohl eine geringere Mediansparquote haben, als auch einen größeren Anteil an Haushalten aufweisen, die keine positive Ersparnis haben. Dieses Bild dreht sich ab einem Einkommen von 2.000€ um und wird vor allem in der Mediansparquote deutlich.

\section{Tabelle 6: Haushaltssparquoten über Einkommensklassen im Panel (2005-2007)}

\begin{tabular}{|c|c|c|c|c|c|c|c|c|}
\hline \multirow{2}{*}{$\begin{array}{l}\text { Haushalts- } \\
\text { nettoeinkommen }\end{array}$} & \multicolumn{4}{|c|}{ abhängig Beschäftigte } & \multicolumn{4}{|c|}{ selbständig Tätige } \\
\hline & MittelwertSQ & MedianSQ & $\mathrm{SQ}<=0$ & obs in $\%$ & MittelwertSQ & MedianSQ & $\mathrm{SQ}<=0$ & obs in $\%$ \\
\hline$<=1000 €$ & $6,0 \%$ & $2,1 \%$ & $45 \%$ & $9,6 \%$ & $5,1 \%$ & $0,0 \%$ & $75 \%$ & $6,7 \%$ \\
\hline $1001 €-1500 €$ & $4,8 \%$ & $2,2 \%$ & $34 \%$ & $17,2 \%$ & $7,7 \%$ & $1,3 \%$ & $50 \%$ & $10,0 \%$ \\
\hline $1501 €-2000 €$ & $6,3 \%$ & $3,6 \%$ & $25 \%$ & $20,7 \%$ & $5,2 \%$ & $3,1 \%$ & $31 \%$ & $13,3 \%$ \\
\hline $2001 €-2500 €$ & $6,3 \%$ & $4,4 \%$ & $24 \%$ & $18,8 \%$ & $6,2 \%$ & $6,0 \%$ & $30 \%$ & $16,7 \%$ \\
\hline $2501 €-3000 €$ & $6,3 \%$ & $4,3 \%$ & $16 \%$ & $14,7 \%$ & $9,5 \%$ & $7,0 \%$ & $21 \%$ & $15,8 \%$ \\
\hline $3001 €-4000 €$ & $8,9 \%$ & $6,1 \%$ & $16 \%$ & $12,0 \%$ & $11,7 \%$ & $8,3 \%$ & $5 \%$ & $17,5 \%$ \\
\hline$>4000 €$ & $11,9 \%$ & $8,3 \%$ & $8 \%$ & $6,9 \%$ & $12,9 \%$ & $13,5 \%$ & $8 \%$ & $20,0 \%$ \\
\hline
\end{tabular}

Quelle: Eigene Berechnung. SAVE 2005-2008. Imputierte Datensätze mit Nr. 1.

Beschränkung auf Selbständige und abh. Beschäftigte, von denen mindestens 2 Beobachtungen vorliegen.

Die berechneten Sparquoten beziehen alle beobachteten Jahre für den jeweiligen Haushalt mit ein.

Diese Ergebnisse zeigen, dass Selbständige vor allem in den unteren Einkommensklassen Schwierigkeiten haben vorzusorgen, was mit dem geringen Einkommen und der damit fehlenden Vorsor-

\footnotetext{
${ }^{23}$ Hochrechnungen vom Nettoeinkommen auf das Bruttoeinkommen sind zwar möglich, jedoch nicht ohne weitgehende Annahmen durchzuführen. Aus diesem Grund wurde auf die Hochrechnung verzichtet.
} 
gefähigkeit einhergeht. Abmildernd wirkt die Tatsache, dass in den Einkommensklassen kleiner gleich $2.000 €$ etwa $30 \%$ aller Selbständigen enthalten sind, im Gegensatz zu etwa $48 \%$ der abhängig Beschäftigten.

\section{Gründe für eine fehlende Vorsorgebereitschaft}

Die fehlende, an der Ersparnis gemessene Vorsorgebereitschaft kann durch die fehlende Vorsorgefähigkeit allein nicht erklärt werden, denn auch in den höheren Einkommensklassen gibt es Selbständige, die nur geringe positive oder gar negative Sparquoten aufweisen. Besonders erstrebenswert ist es daher, den Einfluss verschiedener von der Theorie als wichtig erachteter Faktoren für eine fehlende Sparbereitschaft wie nicht ausreichendes Finanzwissen, eine starke Diskontierung zukünftigen Konsums zusätzlich zum ungenügendem Einkommen herauszuarbeiten. Ebenfalls hilfreich ist ein direkter Vergleich der Sparquote eines Selbständigen zu einem abhängigen Beschäftigten mit ansonsten gleichen Eigenschaften. Dies würde es ermöglichen, den Effekt der Nichtabsicherung in der obligatorischen Altersvorsorge zu identifizieren.

Tabelle 7 vergleicht verschiedene ausgewählte Merkmale von abhängig beschäftigten Haushalten mit selbständigen Haushalten und zeigt deutlich, dass sich die Population der Selbständigen stark von den abhängig Beschäftigten unterscheidet. Selbständige Haushalte sind signifikant älter, die befragten Personen in selbständigen Haushalten sind öfters männlich, besser gebildet und haben ein höheres Finanzwissen. Das Haushaltseinkommen, die Einkommensvarianz, aber auch das erwartete Einkommenswachstum sind für selbständige Haushalte größer als für abhängig Beschäftigte. Auch weisen die befragten Personen der selbständigen Haushalte eine signifikant höhere Risikobereitschaft bezüglich der Karriere auf als auch eine höhere Selbstsicherheit. Beide Aspekte wurden durch eine subjektive Messung erhoben.

Der Grund für diese deutliche Differenz liegt in der Selbstselektion in die Berufsgruppe begründet. Die Variablen, die diesen Selbstselektionsprozess antreiben, beeinflussen sowohl zu erklärende Variablen wie Jahresersparnis oder Vermögen als auch erklärende Variablen wie Einkommen, Bildung und Finanzwissen. Diese Endogenitätsprobleme machen eine echte Identifikation der Effekte von Einkommen, Diskontierung und Finanzwissen auf die Ersparnis oder das Vermögen ohne geeignete Instrumente unmöglich. 


\section{Tabelle 7: Vergleich verschiedener Charakteristika von abhängig Beschäftigten und Selbständigen in 2006}

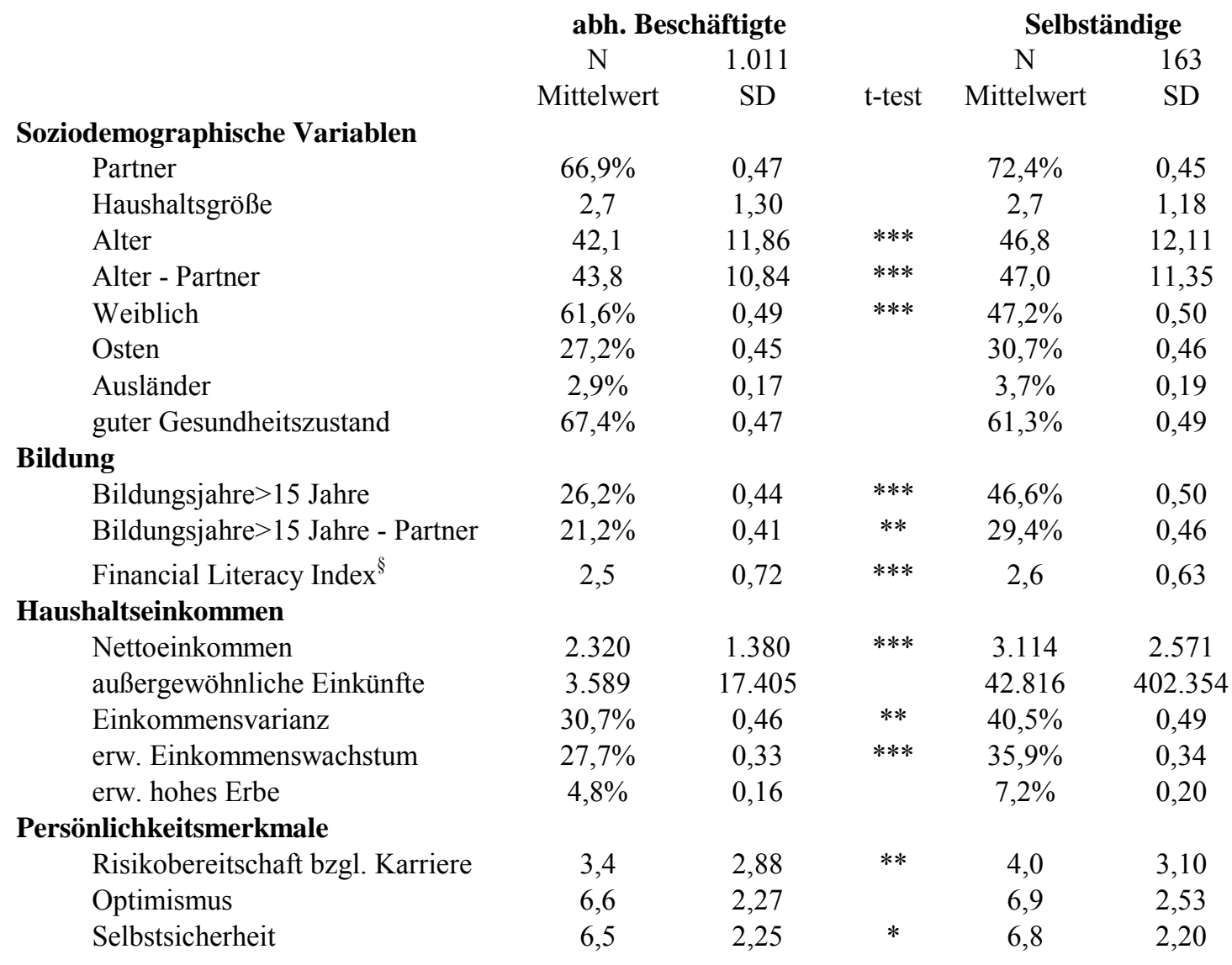

Quelle: Eigene Berechnung. SAVE 2005-2007. Imputierte Datensätze mit Nr. 1.

Die Definition von abh. beschäftigt oder selbständig bezieht sich auf die Haushaltsebene. ttest $\mathrm{H}_{0}: \mathrm{MW}_{\mathrm{B}}=\mathrm{MW}_{\mathrm{S}} ; *: 10 \%$ Signifikanzlevel; ** : $5 \%$; *** : $1 \%$.

$\S$ ausgewertet für 2007.

\subsection{Vorsorgeniveau}

Abschließend wird das Vorsorgeniveau als Ergebnis von Vorsorgefähigkeit und Vorsorgebereitschaft betrachtet. Abbildung 3 zeigt das Vorsorgeniveau gemessen anhand des Nettogesamtvermögens ${ }^{24}$ eines Haushaltes mittels der kumulativen Häufigkeitsverteilung in 2006. Während nur etwa $8 \%$ der abhängig Beschäftigten ein Nettogesamtvermögen von über $400.000 €$ besitzen, haben knapp 23\% der Selbständigen mindestens ein Vermögen von über 400.000€. 47\% der abhängig Beschäftigten haben ein Nettogesamtvermögen von über 50.000€, wohingegen es bei den Selbständigen $67 \%$ sind. Tabelle 8 zeigt in der letzten Zeile, dass etwa $79 \%$ der abhängig Beschäftigten und $87 \%$ der Selbständigen ein positives Nettogesamtvermögen besitzen. Dies liegt bei einem allerdings unkonditionierten Mittelwert von etwa $470.000 €$ für Selbständige etwa drei-

\footnotetext{
${ }^{24}$ Dabei beinhaltet das Nettogesamtvermögen das Geldvermögen (Spareinlagen, Bausparverträge, festverzinsliche Wertpapiere, Aktien(-fonds) und Immobilienfonds, sonstige Wertpapiere), Vermögen für die betriebliche und private Altersvorsorge, Immobilieneigentum, Betriebsvermögen, sonstiges Vermögen (Schmuck, Antiquitäten, ...), abzüglich Kredite und Hypotheken.
} 
mal so hoch wie bei abhängig Beschäftigten mit etwa $148.000 €$. Zusammenfassend ist festzuhalten, dass Selbständige über die Nettogesamtvermögensverteilung hinweg ein größeres Nettogesamtvermögen besitzen als abhängig Beschäftigte.

\section{Abbildung 3: Kumulative Häufigkeitsverteilung des Nettogesamtvermögens in 2006}

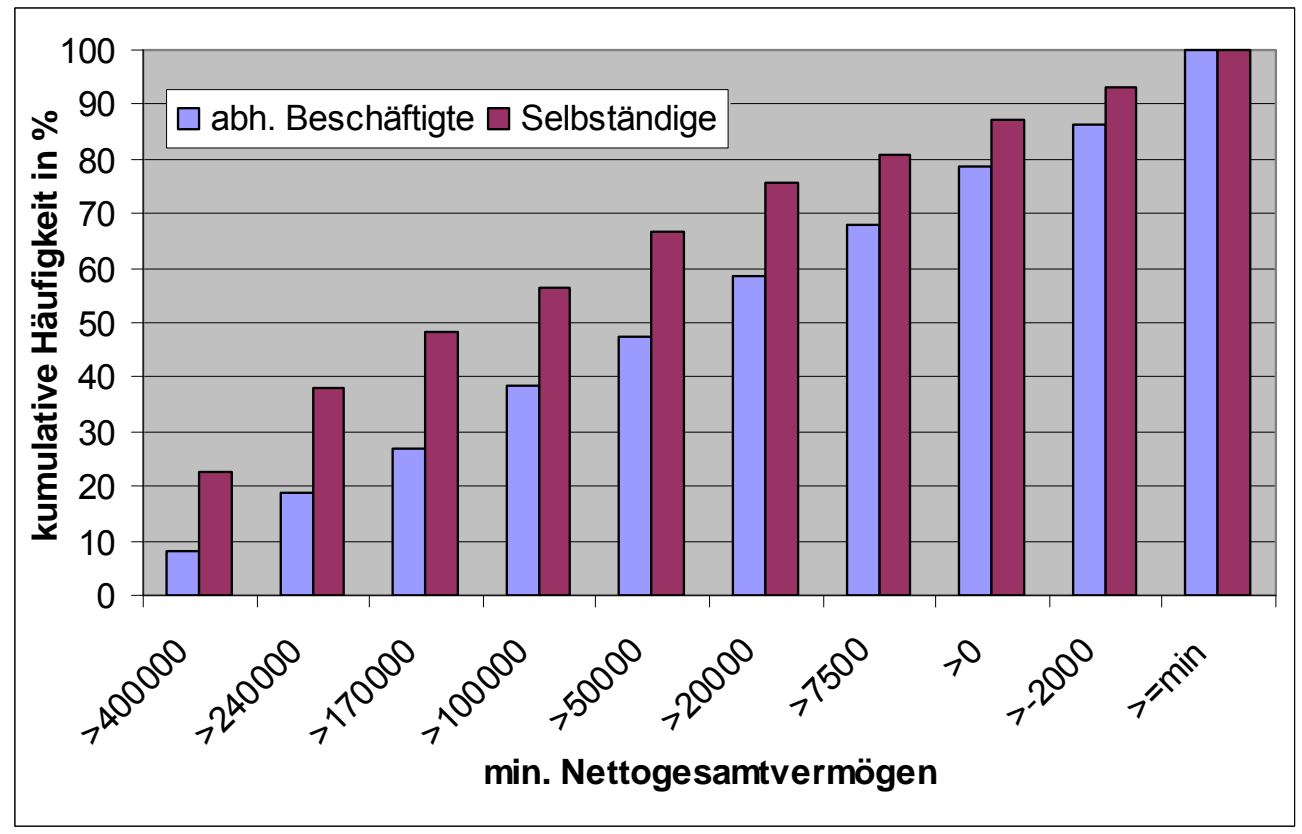

Bei nicht obligatorisch abgesicherten Selbständigen liegt die Vermutung nahe, dass hier ein großer Teil der Ersparnis in das Altersvorsorgevermögen fließt. Tabelle 8 spaltet das Nettogesamtvermögen in seine Einzelbestandteile auf. Die erste Zahlenspalte zeigt den unkonditionierten Mittelwert, der auch Haushalte mit einbezieht, die diese Vermögensklasse nicht besitzen. Daran anschließend folgt der Anteil derjenigen Haushalte, die diese Vermögensklasse besitzen sowie Mittelwert und Median, die auf den Besitz der Vermögensklasse konditioniert sind.

Tabelle 8: Aufteilung des Nettogesamtvermögens in einzelne Vermögensklassen in 2006

\begin{tabular}{|c|c|c|c|c|c|c|c|c|}
\hline & \multicolumn{4}{|c|}{ abhängig Beschäftigte } & \multicolumn{4}{|c|}{ Selbständige } \\
\hline & Mittelwert $^{\mathrm{UC}}$ & Anteil* & Mittelwert ${ }^{\mathrm{C}}$ & Median $^{\mathrm{C}}$ & Mittelwert $^{\mathrm{UC}}$ & Anteil* & Mittelwert $^{\mathrm{C}}$ & Median $^{\mathrm{C}}$ \\
\hline Finanzvermögen & 17.946 & $73,7 \%$ & 24.354 & 10.582 & 40.490 & $71,2 \%$ & 56.895 & 22.353 \\
\hline Nettorealvermögen (ohne BV) & 94.112 & $50,7 \%$ & 190.804 & 150.000 & 207.518 & $66,9 \%$ & 315.417 & 179.325 \\
\hline Altersvorsorgevermögen & 14.606 & $67,8 \%$ & 21.557 & 10.000 & 23.628 & $66,9 \%$ & 35.334 & 20.000 \\
\hline Lebensversicherung & 8.818 & $45,2 \%$ & 19.507 & 10.000 & 16.076 & $50,9 \%$ & 31.570 & 20.000 \\
\hline Betriebl. Altersvorsorge & 3.762 & $27,2 \%$ & 13.831 & 6.000 & 3.349 & $12,9 \%$ & 25.991 & 14.000 \\
\hline Riester/ Rürup (st. gefördert) & 511 & $27,2 \%$ & 1.877 & 1.060 & 248 & $17,2 \%$ & 1.444 & 789 \\
\hline private RV (nicht st. gefördert) & 1.516 & $15,6 \%$ & 9.701 & 5.132 & 3.956 & $25,2 \%$ & 15.727 & 10.000 \\
\hline sonst. Schulden & 5.310 & $31,4 \%$ & 16.935 & 10.000 & 7.143 & $29,4 \%$ & 24.257 & 12.000 \\
\hline Betriebsvermögen (BV) & 26.623 & $3,3 \%$ & 815.621 & 20.000 & 206.000 & $28,2 \%$ & 729.815 & 54.000 \\
\hline Nettogesamtvermögen** & 147.977 & $78,6 \%$ & 191.901 & 96.378 & 470.492 & $87,1 \%$ & 543.791 & 202.000 \\
\hline
\end{tabular}

Quelle: Eigene Berechnung. SAVE 2006-2007. Imputierte Datensätze mit Nr. 1.

$\mathrm{UC}=$ unkonditionierter Mittelwert; $\mathrm{C}=$ auf Besitz konditionierter Mittelwert und Median.

*Anteil der Haushalte, die die entsprechende Vermögenskategorie besitzen.

**Beim Nettogesamtvermögen bezieht sich die Anteilsangabe auf den Besitz eines positiven Nettogesamtvermögens $(>0 €)$. 
Während der Besitz von Finanzvermögen mit 73,7\% für abhängig Beschäftigte und 71,2\% für Selbständige in etwa die gleiche Größenordnung hat, weisen Selbständige mit einem konditionierten Median von 22.353€ und einem konditionierten Mittelwert von etwa $56.895 €$ in beiden GröBen etwa ein doppelt so hohes Finanzvermögen auf wie abhängig Beschäftigte.

50,7\% der abhängig Beschäftigten und 66,9\% der Selbständigen verfügen über Nettorealvermögen, welches sich aus Immobilienvermögen ohne Betriebsvermögen abzüglich der Hypotheken errechnet. Selbständige, die Nettorealvermögen besitzen, haben dabei im Median ein Vermögen von 179.325€ und im Mittelwert von 315.417€. Dabei weisen die konditionierenden Mediane mit einem Unterschied zwischen Selbständigen und abhängig Beschäftigten von etwa $30.000 €$ einen weitaus geringeren Unterschied auf als die konditionierenden Mittelwerte, die etwa $125.000 €$ auseinander liegen.

Beachtenswert ist auch das jeweilige Altersvorsorgevermögen. Für beide Berufsgruppen sind die Anteile der Haushalte, die Altersvorsorgevermögen halten, mit 67-68\% annährend gleich. Mit einem konditionierenden Median von 20.000€ liegen die Selbständigen genau 10.000€ über dem der abhängig Beschäftigten. Im Falle des Mittelwertes von etwa 35.000€ für Selbständige ist der Unterschied leicht größer. Berechnet man nun den Anteil des Altersvorsorgevermögens am Nettogesamtvermögen anhand des unkonditionierten Mittelwertes, so stellt das Altersvorsorgevermögen mit nur 5\% einen sehr geringen Anteil am Nettogesamtvermögen dar. Dies bedeutet, dass Selbständige nicht primär in Altersvorsorgeprodukte zur Altersvorsorge investieren, sondern dies über ein höheres Finanz-, Nettoreal- oder/und Betriebsvermögen abgefangen wird.

Die klassische Lebensversicherung hat dabei unter den Altersvorsorgeprodukten mit $51 \%$ für die Selbständigen den höchsten Verbreitungsgrad. Mit 25\% folgt die private nicht staatlich geförderte Rentenversicherung. Mit einem Verbreitungsgrad von bisher 17\% schließen sich Anwartschaften aus der staatlich geförderten Altersvorsorge an und das Schlusslicht bildet für die Selbständigen die betriebliche Altersvorsorge, die im bisherigen Erwerbsverlauf als abhängig Beschäftigter erworben werden musste. Bei der Höhe der Ansprüche liegen im konditionierten Median die Lebensversicherung mit $20.000 €$ vor der betrieblichen Altersvorsorge mit $14.000 €$ und der privaten nicht staatlich geförderten mit $10.000 €$. Weit abgeschlagen liegt dahinter die staatlich geförderte Altersvorsorge mit knapp $800 €$ im konditionierten Median.

Die Position sonstige Schulden, die sich aus Konsum-, Familien- und Bildungskrediten zusammensetzt, kommt bei Selbständigen und abhängig Beschäftigten mit um die 30\% ähnlich häufig 
vor. Beim konditionierten Median liegen Selbständige mit $12.000 €$ recht nahe an den abhängig Beschäftigten mit $10.000 €$.

Große Unterschiede gibt es dann nochmals beim Betriebsvermögen. Hier unterscheiden sich vor allem wie zu erwarten die Angaben zum Besitz von Betriebsvermögen erheblich. Während 3,3\% der als abhängig beschäftigt klassifizierten Haushalte ein Betriebsvermögen besitzen, geben 28,2\% der selbständigen Haushalte an Betriebsvermögen zu haben. Dieser geringe Anteil für Selbständige resultiert aus der Beschränkung von Betriebsvermögen durch die in SAVE gestellte Frage. ${ }^{25}$ Die konditionierenden Mittelwerte liegen dagegen bei diesen Größenordnungen mit etwa $730.000 €$ für Selbständige und 816.000€ für abhängig Beschäftigte recht nahe beieinander. Der konditionierte Median ist bei den Selbständigen mit 54.000€ höher als bei den abhängig Beschäftigten mit $20.000 €$.

Anschließend kann über die Vermögensaufteilung von Selbständigen festgehalten werden (Abbildung 4), dass der größte und wichtigste Teil mit einem Anteil von knapp über 44\% im unkonditionierten Mittelwert das Nettorealvermögen ist. An zweiter Stelle kommt, obwohl für nur 28\% der Selbständigen relevant, wegen seiner hohen Beträge, das Betriebsvermögen mit knapp unter 44\%. Das Finanzvermögen macht für die Selbständigen etwa 9\% und das Altersvorsorgevermögen nur 5\% aus (allein die private Altersvorsorge macht 4,3\% aus). ${ }^{26}$ Stellt man dies den abhängig Beschäftigten gegenüber, so ist auch hier mit knapp 64\% das Nettorealvermögen der wichtigste Teil. Mit 18\% folgt das Betriebsvermögen und 12\% das Finanzvermögen. Interessant ist der Umstand, dass für abhängig Beschäftigte das Altersvorsorgevermögen mit 10\% das Doppelte zum unkonditionierten Mittelwert des Nettogesamtvermögens beiträgt als für Selbständige mit lediglich 5\%. Somit scheinen verschiedene Altersvorsorgeprodukte für Selbständige nur eine geringe Attraktivität zu haben. Dies kann daran liegen, dass sich beispielweise durch Investitionen in den eignen Betrieb weitaus höhere Renditen erwirtschaften lassen. Ein anderer Grund liegt in der Inflexibilität der meisten Altersvorsorgeprodukte. Selbst Kapitallebensversicherungen sind durch die Länge ihrer Laufzeit und die am Anfang anfallenden Abschlusskosten ein wenig flexibles Finanzinstrument. Gerade das Vorsichtsparmotiv, das Vererbungsmotiv und das Altersvorsorgemotiv beeinflussen sich gegenseitig stark (Ziegelmeyer, 2009b). Treten im Alter unvorhergesehene Ereignisse auf, so kann das Altersvorsorgevermögen oder auch das mögliche Erbe reduziert

\footnotetext{
${ }^{25}$ Frage 106 im SAVE Fragebogen 2007 lautet: „Besitzen Sie bzw. Ihr(e) Partner(in) Betriebsvermögen? Hierunter verstehen wir gewerblich genutzte Gebäude und Grundstücke sowie Anteile an einem Unternehmen, etwa an einer GmbH. Nicht gemeint sind hier Aktien." Es wird nicht nach Ausrüstung (Werkzeuge, Maschinen usw.) und Arbeitsmaterialien gefragt.

${ }^{26}$ Diese Prozentzahlen addieren sich zu mehr als $100 \%$. Sie addieren sich zu $100 \%$ plus dem Anteil der sonstigen Schulden am Nettogesamtvermögen.
} 
werden um den unvorhergesehenen Ereignissen zu begegnen. Kommt man umgekehrt ohne unvorhergesehene Ereignisse wie beispielsweise Gesundheitsprobleme durch das Alter, kann das Vermögen für unvorhergesehene Ereignisse auf das Altersvorsorgevermögen und das zu vergebende Erbe aufgeteilt werden. Ist jedoch das Altersvorsorgevermögen an den Zweck der Altersvorsorge gebunden, schränkt dies die Flexibilität des Vermögens zwischen diesen drei Sparmotiven stark ein.

\section{Abbildung 4: Anteile der einzelnen Vermögensklassen am mittleren Nettogesamtvermögen}

Abhängig Beschäftigte

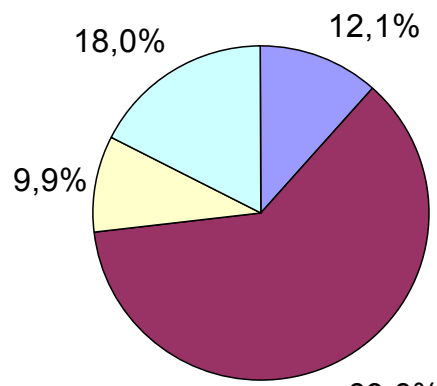

$63,6 \%$
Selbständige

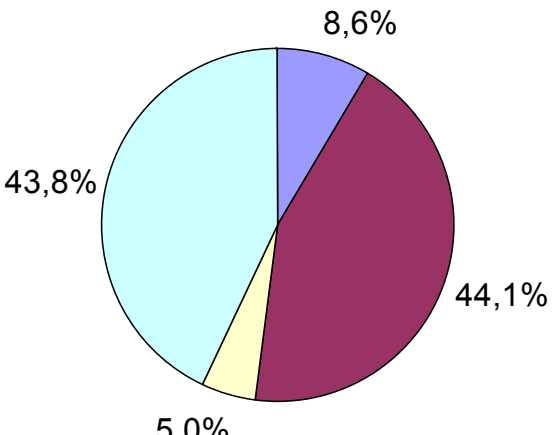

Quelle: Eigene Berechnung. SAVE 2006-2007. Imputierte Datensätze mit Nr. 1.

\section{Tabelle 9: Erwartete Alterseinkommen nach Berufsgruppen auf Individualebene in $\mathbf{2 0 0 6}^{27}$}

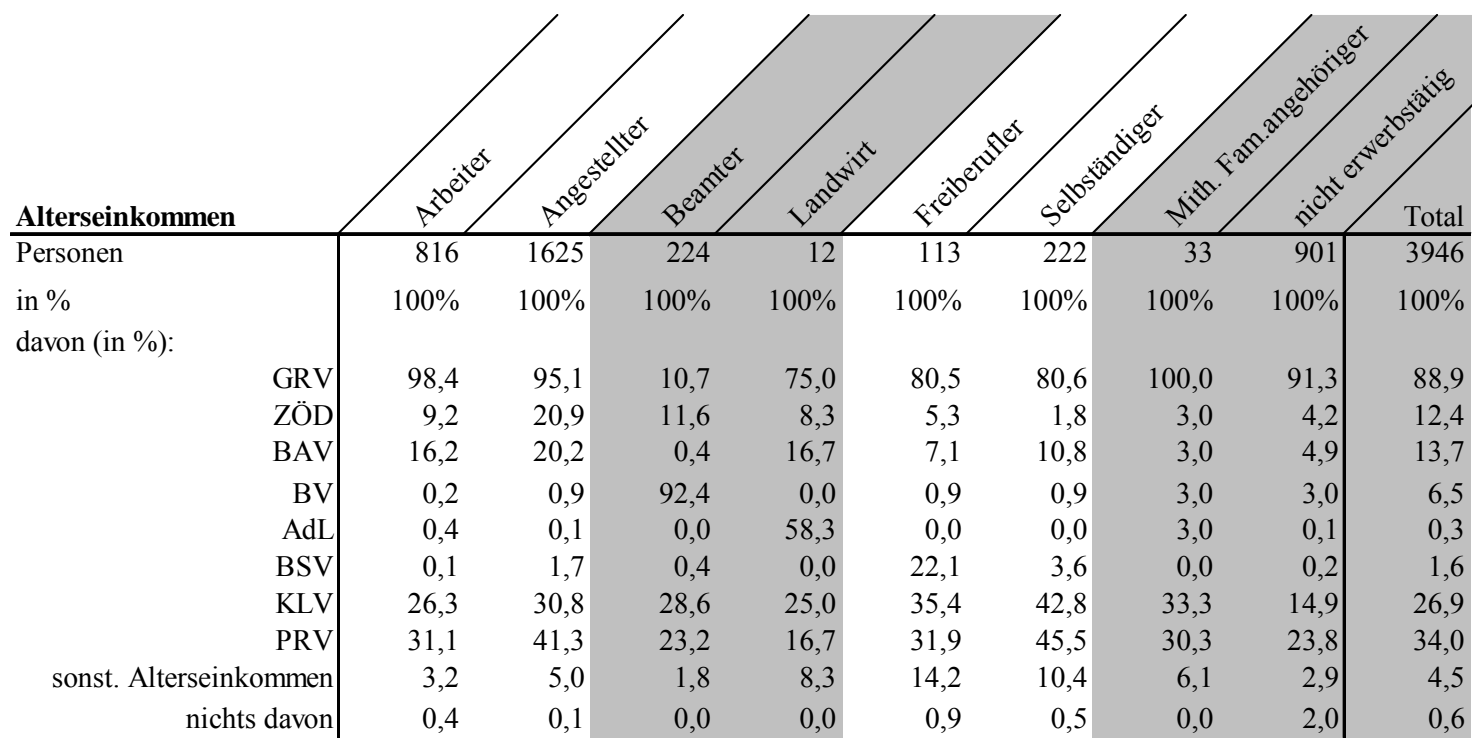

Quelle: Eigene Berechnung. SAVE 2006. Imputierte Datensätze mit Nr. 1.

Bermerkung: Renter ausgeschlossen, da an diese die Frage nicht gestellt wurde.

27 Beschreibung der Abkürzungen: Erste Säule: GRV(gesetzliche Rentenversicherung), BV(Beamtenversorgung), AdL (Altersicherung für Landwirte), BSV (berufsständische Versorgung für Angehörige der verkammerten Freien Berufe); zweite Säule: ZÖD (Zusatzversorgung öffentlicher Dienst), BAV (betriebliche Altersvorsorge in der Privatwirtschaft); dritte Säule: KLV (Kapitallebensversicherung), PRV (Private Rentenversicherung (auch Riester- und Rürup-Renten). 
Obwohl die bisherige Betrachtung die zweite und dritte Säule des Rentensystems mit einschließt, blieb die erste Säule, d.h. die Anwartschaften, die in der obligatorischen Altersvorsorge erworben wurden, außer Betracht. Tabelle 9 zeigt die Angaben über erwartete Alterseinkommen auf Individualebene für 2006. Die Frage lässt zu, dass auch noch in der Zukunft erworbene Anwartschaften mitberücksichtigt werden. ${ }^{28}$ Leider liegen in diesem Fall nur Ja/ Nein Antworten vor, so dass die Höhe der Anwartschaften unbekannt bleibt.

Tabelle 9 zeigt, dass etwa 98\% der Arbeiter und 95\% der Angestellten erwartet, ein Alterseinkommen aus der GRV zu beziehen. Beachtung verdient auch, dass $80-81 \%$ der Selbständigen und Freiberufler Anwartschaften in der GRV erwarten, die sicher zu einem großen Teil aus Zeiten abhängiger Beschäftigung vor der Aufnahme der selbständigen Tätigkeit herrühren. Angaben, dass keine Alterseinkommen zukünftig bezogen werden, sind mit unter einem Prozent für Selbständige und Freiberufler wie auch für alle anderen Gruppen außer bei den Nichterwerbstätigen sehr gering. Die Zahlen über erwartete Alterseinkommen aus Kapitallebensversicherung liegen unter den Werten zum aktuellen Besitz von Kapitallebensversicherungen von 51\% aus Tabelle 8. Dies liegt daran, dass nur ein Teil der Kapitallebensversicherungen zur Altersvorsorge genutzt wird. Die Prozentsätze für eine private Rentenversicherung liegen vor allem für die Selbständigen mit knapp 46\% in Tabelle 9 über den aktuellen Werten von 37\% (Kategorien staatlich und nicht staatlich geförderte Altersvorsorge aus Tabelle 8). Dies kann als Indiz gesehen werden, dass Selbständige im späteren Teil ihres Lebens noch Anwartschaften in diesen Bereichen erwerben möchten, geht aber auch auf die Konstruktion der Gruppe der nicht obligatorisch abgesicherten Selbständigen zurück, die in dieser Arbeit verwendet wird.

Im bisher gezeichneten Bild des Nettogesamtvermögens für Selbständige wurden wichtige Aspekte noch nicht beleuchtet. Zum einen kann ein Teil des höheren Vermögens der Selbständigen auf ihr höheres durchschnittliches Alter zurückzuführen sein (siehe Tabelle 7). Zum anderen beschränkte sich die bisherige Betrachtung auf Besitz einer Anlageklasse, Mittelwert und Median. Abbildung 5 schließt diese Lücke, indem über unterschiedliche Altersklassen verschiedene Nettogesamtvermögensperzentile in 2007 abgetragen werden.

Der Median des Nettogesamtvermögens steigt von 69.000€ für die Altersgruppe unter 36 Jahre bis hin zu 265.000€ für die über 55-Jährigen. Betrachtet man das 25\% Perzentil von 57.000€ zum 75\% Perzentil von 574.000€ für die über 55-Jährigen, so fällt die starke Ungleichverteilung des Nettogesamtvermögens auf.

\footnotetext{
${ }^{28}$ Die entsprechende Frage aus dem SAVE Fragebogen lautet: „Welche der aufgeführten Arten von Alterseinkommen werden Sie und Ihre(e) Partner(in) voraussichtlich im Alter beziehen?“
} 


\section{Abbildung 5: Nettogesamtvermögens über Altersklassen der befragten Person in 2007}

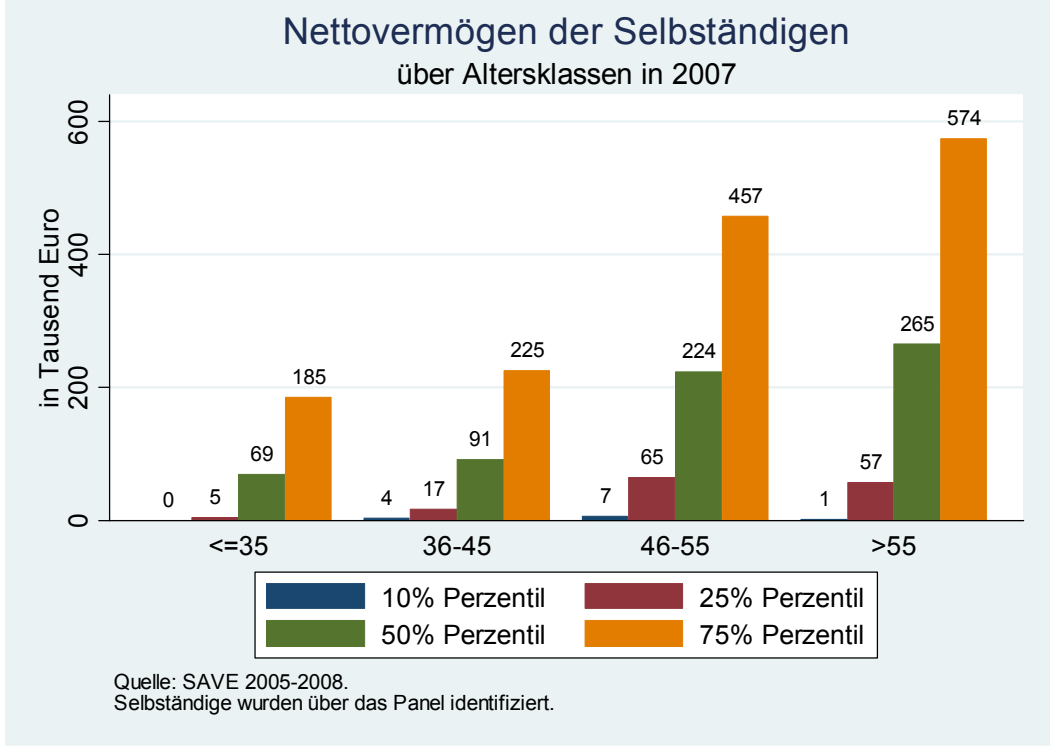

An dieser Stelle wird auf eine einfache Vergleichsrechnung zurückgegriffen, um die Frage zu beantworten, inwieweit Selbständige ohne die Berücksichtigung der Anwartschaften aus der ersten Säule in der Lage sind, aus ihrem bereits erworbenen Vermögen eine Annuität zu finanzieren, die die Grundsicherung im Alter sicherstellt. Eine solche Rechnung ist nur für die älteste Altersklasse von über 55 Jahren sinnvoll, da in diesem Fall die Möglichkeiten das Vermögen stärker durch ein verändertes Spar- und Arbeitsverhalten zu verändern eher begrenzt sind als für jüngere Altersklassen. Greift man auf die gleichen Annahmen zurück wie bei der Berechnung des minimalen Sparbetrages im Abschnitt 5.2 und im Anhang D, kommt man bei Männern im Alter von 65 Jahren auf einen Vermögensbedarf von $111.417 €$, wenn eine reale Annuität von $647 €$ pro Monat bis ans Lebensende bezogen werden soll. Bei Frauen erhöht sich dieser Betrag durch die höhere Lebenserwartung auf $131.418 €$. Dies stellt auch den Vermögensbedarf von Einpersonenhaushalten dar. Zweipersonenhaushalte ${ }^{29}$ dagegen erzielen durch das Zusammenleben gewisse Skaleneffekte. Aus diesem Grund wird der Vermögensbedarf für Männer und Frauen addiert und anschließend durch die Quadratwurzel von 2 geteilt, was einem Betrag von $171.710 €$ entspricht.

Für die Klasse der über 55-Jährigen sind insgesamt 26\% Prozent der als selbständig klassifizierten Haushalte nicht in der Lage den Vermögensbedarf zur Abdeckung der Grundsicherung im Alter

\footnotetext{
${ }^{29}$ Diese Kalkulation unterscheidet nur zwischen 1 und 2 Personenhaushalten, weil diese ab einem Alter von 65 Jahren der Normalfall sind (in SAVE 2006 stellen die Ein- und Zweipersonenhalte etwa 91\% der Haushalte dar, für die das Alter des Befragten über 65 Jahre ist). Auch wenn noch mehr Personen im Haushalt leben, so wird angenommen, dass das Vermögen ausschließlich für die Altersvorsorge der befragten Person und deren Partner verwendet wird.
} 
aus ihrem aktuellen Vermögen zu gewährleisten. ${ }^{30}$ Auch eine Verzinsung des Vermögens zusammen mit einer Fortschreibung des derzeitigen Sparverhaltens reduziert diesen Prozentsatz nicht merklich. ${ }^{31} \mathrm{Da}$ in diese Betrachtung die Anwartschaften aus den obligatorischen Alterssicherungssystemen wie auch Verhaltensanpassungen nicht einbezogen werden können, kann dieser Prozentsatz als eine obere Grenze angesehen werden.

\section{Zusammenfassung und Schlussfolgerung}

Diese Arbeit untersucht das Altersvorsorge-Verhalten von Selbständigen mit Hilfe des SAVE Datensatzes 2005-2008. Die Komplexität des Altersvorsorge-Verhaltens lässt die Aufteilung der Untersuchung in Vorsorgefähigkeit, Vorsorgebereitschaft und Vorsorgeniveau auch aus theoretischer Sicht als sinnvoll und ratsam erscheinen. Der SAVE Datensatz erlaubt die Messung dieser Konzepte durch die Erfragung des Nettoeinkommens, der Jahresersparnis, des Vermögens mit einer weiten Reihe anderer themenrelevanter Variablen. Das Panel erweitert dabei den Beobachtungshorizont einer Querschnittsanalyse auf einen Mehrjahreszeitraum.

Die Analyse zeigt, dass selbständige Individuen sowie Haushalte mit selbständigem Haupteinkommensbezieher sowohl im Median als auch im Mittelwert ein höheres Nettoeinkommen aufweisen als abhängig Beschäftigte, was vor allem an einer höheren Dichte von hohen Einkommen liegt. Jedoch gibt es auch mehr Selbständige am unteren Ende der Verteilung, obwohl für die Selbständigen keine Beiträge zur Sozialversicherung abgeführt werden. Die anschließende Vorsorgefähigkeitsanalyse anhand der relativen und absoluten Armutsgrenzen unterstreicht die Bedeutung des Einbezugs der Ressourcen des gesamten Haushaltes in die Analyse. Der Anteil der Selbständigen, die selbst auf Haushaltsebene keine ausreichende Vorsorgefähigkeit aufweisen ist mit 11-12\% für die absolute Armutsgrenze mit für ein Alterseinkommen auf Grundsicherungsniveau adäquaten Ersparnis und 21-22\% für die relative Armutsgrenze mit Ersparnis auf einem hohen Niveau.

Die anschließende Vorsorgebereitschaftsanalyse anhand der Jahresgesamtersparnis macht deutlich, dass Haushalte mit selbständigem Haupteinkommensbezieher im Schnitt mehr sparen als Haushalte mit abhängig beschäftigtem Haupteinkommensbezieher. Dieser Vergleich berücksich-

\footnotetext{
${ }^{30}$ Das Ergebnis ist robust in Bezug auf die Definition von Selbständigkeit für den Haushalt. Berücksichtigt man für den Status der Selbständigkeit nicht wie hier getan das Panel, sondern nur das aktuelle Jahr sind 24\% der Haushalte nicht in der Lage den errechneten Vermögensbedarf aufzubringen.

${ }^{31} \mathrm{Da}$ Lohnprofile für Selbständige in Deutland nach Wissen des Autors bisher nicht berechnet wurden, wurde der aus drei Jahren gemittelte Sparbetrag bis zu einem Alter von 65 Jahren fortgeschrieben. Alle anderen Annahmen entsprechen den in Anhang D gemachten Annahmen.
} 
tigt nicht eventuell erworbene Rentenanwartschaften in der ersten Säule. Ein solches Ergebnis zeigen sowohl die Haushaltsparquoten auf jährlicher Basis wie auch die Sparquoten im Panel.

Dieses Ergebnis gilt jedoch nur im Mittelwert und Median. Die Einkommensspreizung der Haushalte mit selbständigem Haupteinkommensbezieher ist jedoch sehr hoch. Alarmierend sind hier vor allem die geringen Sparquoten in den Haushaltsnettoeinkommensklassen bis zu 2.000€. In diesen sparen sogar abhängig Beschäftigte auf geringem Niveau mehr als Selbständige.

Haushalte mit selbständigem Haupteinkommensbezieher haben im Schnitt ein etwa dreimal so hohes Nettogesamtvermögen wie Haushalte mit abhängig beschäftigtem Haupteinkommensbezieher. Erstaunlich ist jedoch, dass bei der Betrachtung der einzelnen Vermögenskategorien das durchschnittliche Altersvorsorgevermögen (betrieblich und privat) bei Selbständigen mit nur 5\% einen kleineren Anteil am durchschnittlichen Nettogesamtvermögen einnimmt als bei den abhängig Beschäftigten mit etwa $10 \%$. Jedoch ist das Nettogesamtvermögen von Haushalten mit selbständigem Haupteinkommensbezieher ungleich verteilt. Diese Ungleichverteilung führt dazu, dass etwa $26 \%$ in der Klasse der über 55-Jährigen nicht in der Lage sind den Vermögensbedarf zur Abdeckung der Grundsicherung ab 65 Jahren zu gewährleisten. Diese Betrachtung klammert allerdings die in obligatorischen Altersvorsorgewerken erworbenen Anwartschaften und Verhaltensänderung aus und sollte daher als obere Grenze angesehen werden.

Die Verwendung der SAVE Daten ermöglicht ein umfassenderes Bild von dem Vorsorgepotential und der daraus resultierenden Schutzbedürftigkeit von Selbständigen vor möglicher Altersarmut zu zeichnen. Es zeigt sich, dass dem größten Teil der Selbständigen ausreichende Mittel für eine entsprechende Altersvorsorge zur Verfügung stehen, so dass für diese Gruppe Altersarmut ausgeschlossen sein dürfte. Doch für einen gewissen kleineren Teil ist die Gefahr von Altersarmut nicht von der Hand zu weisen.

Aus diesen Ergebnissen sollte jedoch nicht vorschnell auf ein generelles Schutzbedürfnis von Selbständigen geschlossen werden, mit dem eine generelle Vorsorgepflicht bzw. Versicherungspflicht für Selbständige gerechtfertigt werden könnte. Dies erfordert eine wesentlich differenzierte sozialpolitische Abwägung der mit einer solchen Lösung verbundenen Nachteile. Selbst wenn man eine Versicherungspflicht als notwendig erachten würde, bedeutete dies nicht, dass diese in Form einer Einbeziehung in die Gesetzliche Rentenversicherung (Stichwort: Erwerbstätigenversicherung) erfolgen sollte. Denn hier müssen die negativen Effekte einer Ausweitung der demographieanfälligen umlagefinanzierten Rentenversicherung, und vor allem die damit verbundenen negativen Anreizeffekte für das Arbeitsangebot dieser Personengruppe berücksichtigt werden. 


\section{Literatur}

Angeletos, G.-M., D. Laibson, et al. (2001): "The Hyperbolic Consumption Model: Calibration, Simulation, and Empirical Evaluation." Journal of Economic Perspectives, 15(3), 47-68.

Banks, J., C. Emmerson, Z. Oldfield, G. Tetlow (2005): "Prepared for Retirement? The Adequacy and Distribution of Retirement Resources in England." The Institute for Fiscal Studies: London.

Börsch-Supan, A., M. Coppola, L. Essig, A. Eymann, D. Schunk (2008): “The German SAVE study. Design and Results.“ MEA Study Nr. 6, MEA Mannheim.

Breyer, F., W. Buchholz (2007): „Ökonomie des Sozialstaats.“ Springer-Verlag, Berlin, Heidelberg.

Bucher-Koenen, T. (2009): "Financial Literacy and old-age provision in Germany - Evidence from SAVE 2008.” Unpublished Working Paper, MEA Mannheim.

Bundesministerium der Finanzen (Hrsg.) (2004): „Bericht über die Höhe des Existenzminimums von Erwachsenen und Kindern für das Jahr 2005 (Fünfter Existenzminimumbericht).“" Monatsbericht 02.2004, 89-95.

Bundesministerium für Arbeit und Soziales (Hrsg.) (2008): „Übersicht über das Sozialrecht.“ 5. Auflage, Nürnberg.

Bundesregierung (Hrsg.) (2006): „Bericht über die Höhe des Existenzminimums von Erwachsenen und Kindern für das Jahr 2008 (Sechster Existenzminimumbericht).“ Drucksache 16/3265, Unterrichtung durch die Bundesregierung.

Bundesregierung (Hrsg.) (2008): „Lebenslagen in Deutschland - Der dritte Armuts- und Reichtumsbericht der Bundesregierung." http://www.bmas.de/coremedia/generator/26742 /property $=\mathrm{pdf} / \mathrm{dritter}$ armuts und reichtumsbericht.pdf, letzter Zugriff: 20.7.2009.

Deutsche Rentenversicherung Bund (Hrsg.) (2008): „Rentenversicherung in Zahlen 2008, Berlin.

Deutsche Rentenversicherung Bund (2009): „Grundsicherung.“ Homepage: http://www.deutsche-rentenversicherung-bund.de/nn_11962/SharedDocs/de/Navigation/ Rente/Leistungen/grundsicherung/Beispiele_node.html_nnn=true, letzter Zugriff: 20.7.2009.

Dräther, H., U. Fachinger, A. Oelschläger (2001): „Selbständige und ihre Altersvorsorge: Möglichkeiten der Analyse anhand der Mikrozensen und erste Ergebnisse.“ MPRA Paper No. 1130 .

Fachinger, U. (2002): „Sparfähigkeit und Vorsorge gegenüber sozialen Risiken bei Selbständigen: Einige Informationen auf der Basis der Einkommens- und Verbrauchsstichprobe 1998.“ MPRA Paper No. 1126.

Fachinger U., A. Oelschläger, W. Schmähl (2004): „Alterssicherung von Selbständigen: Bestandsaufnahme und Reformoptionen.“ LIT Verlag, Berlin-Hamburg-Münster. 
Frederick, S., G. Loewenstein, et al. (2002): "Time Discounting and Time Preference: A Critical Review." Journal of Economic Literature, 40(2), 351-401.

Friedman, M. (1957): “A Theory of the Consumption Function.” Princeton: Princeton University Press.

Glenberg, A. M., M. E. Andrzejewski (2008): "Learning from data - an introduction to statistical reasoning." 3. ed., New York [u.a.].

Heien, T., K. Kortmann, C. Schatz (2007): „Altersvorsorge in Deutschland 2005.“ DRVSchriften, Band 75.

Institut für Freie Berufe (2005): „Freie Berufe 2005 im Zahlenbild. Zuwächse auf der Grundlage unterschiedlicher Entwicklungen." Nürnberg: http://www.ifb.uni-erlangen.de/pdf/ Info-2005-01.pdf, letzter Zugriff: 27.7.2009.

Kohlmeier, A. (2009): „Die Ausweitung des Versichertenkreises der Gesetzlichen Rentenversicherung - Bestimmungsgründe und Verteilungswirkungen." Dissertationsschrift, Technische Universität Darmstadt.

Laibson, D., J. Tobacman, et al. (2007): "Estimating Discount Functions with Consumption Choices over the Lifecycle.” University of Oxford Discussion Paper Series.

Lusardi, A. (1999): “Information, Expectations, and Savings for Retirement.” In H. Aaron (ed.): "Behavioral Dimensions of Retirement Economics." Washington, D.C.: Brookings Institution and Russell Sage Foundation, 81-115.

Lusardi, A. (2003): "Planning and Saving for Retirement." Working Paper, Dartmouth College, http://www.dartmouth.edu/ alusardi/Papers/Lusardi_pdf.pdf, letzter Zugriff: 3.8.2009.

Lusardi, A., J. Beeler (2007): "Saving Between Cohorts: The Role of Planning." In B. Madrian, O. Mitchell, B. Soldo (eds): "Redefining Retirement. How Will Boomers Fare?" Oxford: Oxford University Press.

Lusardi, A., O. S. Mitchell (2007): "Baby boomers retirement security: The role of planning, financial literacy and housing wealth.” Journal of Monetary Economics, 54, 205-224.

Lusardi, A., O. S. Mitchell (2009): "How Ordinary Consumers Make Complex Economic Decisions: Financial Literacy and Retirement Readiness." Working paper, http://www.dartmouth.edu/ alusardi/Papers/LusardiMitchellOrdinaryConsumers.pdf, letzter Zugriff: 3.8.2009.

Merz, J. (2006): „Polarisierung der Einkommen von Selbständigen? Zur Dynamik der Einkommensverteilung und der hohen Einkommen von Selbstständigen und abhängig Beschäftigten.“ MPRA Paper No. 5743.

Modigliani, F., R. Brumberg (1954): "Utility analysis and the consumption function: An interpretation of cross-section data." In: Flavell, J. H. and L. Ross (Eds.): "Social Cognitive Development Frontiers and Possible Futures." Cambridge, NY: University Press.

OECD (Hrsg.) (2005): "What are equivalence scales?" OECD Social Policy Division; http://www.oecd.org/dataoecd/61/52/35411111.pdf, letzter Zugriff: 3.8.2009. 
Rische, H. (2008): „Weiterentwicklung der gesetzlichen Rentenversicherung zu einer Erwerbstätigenversicherung." RVaktuell 1/2008.

Sachverständigenrat zur Begutachtung der gesamtwirtschaftlichen Entwicklung (2006/2007): „Widerstreitende Interessen - ungenutzte Chancen.“ Jahresgutachten 2006.

Scholz, J. K., A. Seshadri, S. Khitatrakun (2006): “Are Americans Saving 'Optimally' for Retirement?” Journal of Political Economy, 114(4), 607-643.

Schulze Buschoff, K. (2007): „Neue Selbstständige - Die Entwicklung in Deutschland und in anderen europäischen Ländern.“ Beitrag zur DGB-Tagung zum Grünbuch der EUKommission, 13. Februar 2007.

Schunk, D. (2008): “A Markov Chain Monte Carlo Algorithm for Multiple Imputation in Large Surveys.” Advances in Statistical Analysis, 92, 101-114.

Soman, D., G. Ainslie, et al. (2005): "The Psychology of Intertemporal Discounting: Why are Distant Events Valued Differently from Proximal Ones?" Marketing Letters, 16(3/4), 347360 .

Sozialgesetzbuch (2003): „Grundsicherung im Alter und bei Erwerbsminderung.“ Zwölftes Buch (XII) - Sozialhilfe - (Artikel 1 des Gesetzes vom 27. Dezember 2003, BGB1. I S. 3022) viertes Kapitel, http://bundesrecht.juris.de/sgb_12/, letzter Zugriff: 3.8.2009.

Windhövel, K., C. Funke, J.-C. Möller (2008): „Fortentwicklung der gesetzlichen Rentenversicherung zu einer Erwerbstätigenversicherung. Konsequenzen bei Einkommensverteilung, Beitragssatz und Gesamtwirtschaft." Abschlussbericht der Prognos AG für die Hans Böckler Stiftung.

Ziegelmeyer, M. (2009a): "Documentation of the logical imputation using the panel structure of the 2003-2008 German SAVE Survey." MEA Discussion Paper 173-09, MEA Mannheim.

Ziegelmeyer, M. (2009b): "Analysis of the Precautionary Saving Motive Based on a Subjective Measure (SAVE 2005-2007).” MEA Study Nr. 7, MEA Mannheim. 


\section{Anhang A: Datensätze}

Für die Untersuchung des Altersvorsorgeverhaltens von Selbständigen kommen verschiedene, in Tabelle 10 aufgeführte, Datensätze in Frage. Der Überblick beschränkt sich auf die Aspekte der jeweiligen Umfragen, die zur Analyse des Altersvorsorge-Verhaltens von Selbständigen notwendig sind. Dabei müssen Selbständige und eventuell verschiedene Untergruppen (Soloselbständige, nicht obligatorisch abgesicherte Selbständige) identifiziert werden können. Ferner spielt die Stichprobengröße und deren mögliche Beschränkung eine Rolle. Eine Analyse von Vorsorgefähigkeit, Vorsorgebereitschaft und Vorsorgeniveau für eine umfassende Untersuchung ist notwendig, wozu Angaben zu Einkommen, Ersparnis und Vermögen notwendig sind. Angaben über die entsprechenden Erwerbsverläufe vervollständigen das Bild.

\section{Tabelle 10: Datensatzübersicht}

\begin{tabular}{|c|c|c|c|c|c|c|c|c|c|c|c|}
\hline Datensatz & 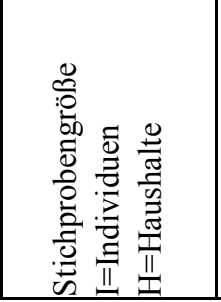 & 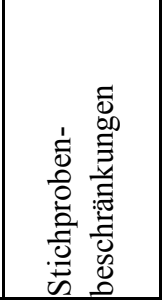 & 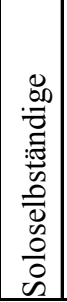 & 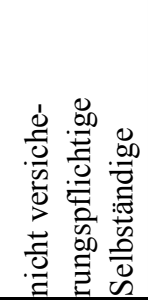 & 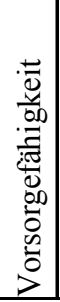 & 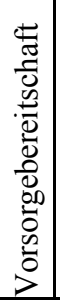 & 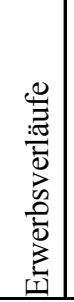 & & 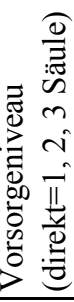 & & 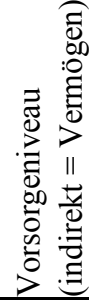 \\
\hline & & & & & & & & 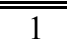 & $\overline{21}$ & 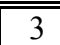 & \\
\hline$\overline{\text { AVID } 2005}$ & $13.716 \mathrm{I}$ & 1942-1961 & 0 & $\bar{X}$ & $\overline{0}$ & 0 & $\mathrm{X}$ & $\mathrm{X}$ & $\bar{X}$ & $\mathrm{X}$ & 0 \\
\hline ASID 2003 & $37.262 \mathrm{I}$ & $|1923-1948|$ & 0 & $\mathrm{X}$ & $\mathrm{X}$ & 0 & $\mathrm{X}$ & $\mathrm{J} / \mathrm{N}$ & $\mathrm{J} / \mathrm{N}$ & $\mathrm{J} / \mathrm{N}$ & 0 \\
\hline Mikrosensus 2005, 2006 & ca. 0,8 Mio I & & $\mathrm{X}$ & 0 & $\mathrm{X}$ & 0 & 0 & 0 & 0 & 0 & 0 \\
\hline Einkommensteuerstatistik 2001 & ca. 3 Mio. I & $*$ & 0 & 0 & $\mathrm{X}$ & 0 & 0 & 0 & 0 & 0 & 0 \\
\hline EVS 2003 & $53.400 \mathrm{HH}$ & $* *$ & 0 & $1 / 2$ & $\mathrm{X}$ & $\mathrm{x}$ & 0 & 0 & 0 & $\mathrm{X}$ & $X$ \\
\hline SOEP 2002, 2007 & $11.202 \mathrm{HH}^{\dagger}$ & & $\mathrm{X}$ & 0 & $\mathrm{X}$ & $\mathrm{x}$ & $\mathrm{X}$ & 0 & 0 & $\mathrm{X}$ & $\mathrm{X}$ \\
\hline SAVE 2005-2008 & $2305-3474 \mathrm{HH}$ & & 0 & $1 / 2$ & $\mathrm{X}$ & $\mathrm{X}$ & $1 / 2$ & $\mathrm{~J} / \mathrm{N}$ & $\mathrm{X}$ & $\mathrm{X}$ & $\mathrm{X}$ \\
\hline
\end{tabular}

Erklärung: 0:=keine Angabe; $\mathrm{X}:=$ enthalten; 1/2:=teilweise enthalten; $\mathrm{J} / \mathrm{N}:=$ nur als Ja/Nein Frage enthalten.

* Nicht erfasst ist nicht steuerpflichtiges und nicht versteuertes Einkommen.

** Monatseinkommen über $18.000 €$ abgeschnitten.

${ }^{\dagger}$ Standard-Stichprobe in 2002.

Die AVID 2005 ist in Bezug auf die direkten Altersvorsorgemaßnahmen (erste, zweite und dritte Säule der Altersvorsorge) der detaillierteste Datensatz. Allerdings bezieht sich der Datensatz im Umfragejahr 2002 auf die 40- bis unter 60-Jährigen. Ähnlich verhält es sich mit der ASID 2003, die 55- bis 80-Jährige im Befragungsjahr 2003 enthält. Beide Umfragen sind somit nicht in der Lage die neusten Entwicklungen am Arbeitsmarkt für alle Erwerbstätigen abzubilden. Dies ist 
insofern wichtig, weil Altersarmut laut dem Dritten Armuts- und Reichtumsbericht der Bundesregierung (2008) zurzeit noch kein aktuelles Problem darstellt. ${ }^{32}$

Der Mikrozensus und die Einkommensteuerstatistik kommen für eine Untersuchung möglicher Altersarmut von Selbständigen nur bedingt in Frage, da diese Datensätze nur eine Vorsorgefähigkeitsanalyse mit Hilfe des Einkommens zulassen. Die EVS geht darüber hinaus und erlaubt zusätzlich die Sparbereitschaft der Haushalte sowie indirekte Altersvorsorgemaßnahmen (Vermögen ohne die drei Säulen der Altersvorsorge) in die Betrachtung mit einzubeziehen. Ferner wird das Vermögen für die private Altersvorsorge erfasst. Die Vermögensfragen des SOEP aus den Jahren 2002 und 2007 ermöglichen die gleiche Analysebandbreite wie in der EVS. Ferner stehen durch die Paneldimension Erwerbshistorien zur Verfügung und Soloselbständige können eindeutig identifiziert werden. Ein Nachteil des SOEP besteht allerdings in der Befragung der aktuellen Ersparnis. ${ }^{33}$ Diese wird als Residualgröße erfragt und es bleibt unklar, ob beispielsweise Beiträge für Riester- oder Lebensversicherungsverträge Berücksichtigung finden, da diese oftmals als Daueraufträge den Betrag auf dem Girokonto vermindern. Auch unregelmäßig zurückgelegte Beträge bleiben unberücksichtigt.

Die seit 2001 vom Mannheimer Forschungsinstitut Ökonomie und demographischer Wandel (MEA) in Zusammenarbeit mit TNS-Infratest durchgeführte SAVE Befragung ermöglicht es hingegen, eine Vorsorgefähigkeits-, Vorsorgebereitschafts- wie auch eine Vorsorgeniveauanalyse von Selbständigen und abhängig Beschäftigten durchzuführen. Siehe dazu Abschnitt 4.

\footnotetext{
32 2,3\% der Menschen ab 65 Jahren bezogen eine Grundsicherung im Alter und bei Erwerbsminderung am Ende des Jahres 2006 (Seite 5 der Kurzfassung).

${ }^{33}$ Frage 52 im SOEP Fragebogen 2007 lautet: „Bleibt Ihnen in der Regel monatlich ein gewisser Betrag übrig, den Sie sparen oder zurücklegen können, etwa für größere Anschaffungen, für Notlagen oder zur Vermögensbildung? Wenn ja, welcher Betrag etwa?“
} 


\section{Anhang B: Vergleich SAVE mit Mikrozensus und EVS}

\begin{tabular}{|c|c|c|c|c|c|c|}
\hline & 2005 & & 2006 & & 2003 & 2003 \\
\hline & SAVE & Mikrozensus & SAVE & Mikrozensus & EVS & EVS $^{1}$ \\
\hline $\begin{array}{l}\text { Personen } \\
\text { in Prozent }\end{array}$ & $\begin{array}{r}3824 \\
100 \%\end{array}$ & $\begin{array}{r}395396 \\
100 \%\end{array}$ & $\begin{array}{r}5818 \\
100 \%\end{array}$ & \begin{tabular}{r|}
412242 \\
$100 \%$
\end{tabular} & $\begin{array}{r}80369 \\
100 \%\end{array}$ & $\begin{array}{r}80369 \\
100 \%\end{array}$ \\
\hline Arbeiter & $14.5 \%$ & $14.9 \%$ & $14.7 \%$ & $14.8 \%$ & $10.0 \%$ & $133 \%$ \\
\hline Angestellter & $27,7 \%$ & $28,0 \%$ & $28,7 \%$ & $29,1 \%$ & $33,7 \%$ & $27,9 \%$ \\
\hline Beamter & $3,5 \%$ & $3,2 \%$ & $4,1 \%$ & $3,2 \%$ & $7,2 \%$ & $3,6 \%$ \\
\hline Selbständiger & $7,6 \%$ & $6,0 \%$ & $7,3 \%$ & $6,1 \%$ & $4,0 \%$ & $4,4 \%$ \\
\hline Mithelf. Familienangehöriger & $0,6 \%$ & $0,6 \%$ & $0,8 \%$ & $0,6 \%$ & $0,3 \%$ & $0,2 \%$ \\
\hline in keiner Weise erwerbstätig & $46,1 \%$ & $47,3 \%$ & $44,5 \%$ & $46,3 \%$ & $44,8 \%$ & $50,6 \%$ \\
\hline Total & $100,0 \%$ & $100,0 \%$ & $100,0 \%$ & $100,0 \%$ & $100,0 \%$ & $100,0 \%$ \\
\hline
\end{tabular}

Quellen: Scientific Use-files des Mikrozensus 2005, 2006 und EVS 2003; SAVE 2005 und 2006.

Bemerkung: Mikrozensus und EVS Stichproben auf Individuen über 17 Jahre beschränkt.

${ }^{1}$ Gewichtet mit Hochrechnungsfaktoren für Deutschland.

\section{Tabelle 12: Haushaltsnettoeinkommen von Selbständigen in SAVE, Mikrozensus und EVS nach Berufsstand der befragten Person ${ }^{35}$}

\begin{tabular}{r|rr|rr|rr}
\multicolumn{1}{l|}{$\begin{array}{r}\text { Haushalts- } \\
\text { nettoeinkommen }\end{array}$} & $\mathbf{2 0 0 5}$ & $\mathbf{2 0 0 6}$ & $\mathbf{2 0 0 3}$ & 2003 \\
\hline$<500$ & Mikrozensus(*) & SAVE & Mikrozensus(*) & SAVE & EVS & EVS $^{1}$ \\
\hline $500-899$ & $2,3 \%$ & $2,7 \%$ & $1,6 \%$ & $2,7 \%$ & $1,1 \%$ & $1,6 \%$ \\
$900-1499$ & $5,5 \%$ & $3,8 \%$ & $5,2 \%$ & $2,7 \%$ & $1,5 \%$ & $2,5 \%$ \\
$1500-1999$ & $13,4 \%$ & $13,1 \%$ & $14,1 \%$ & $10,8 \%$ & $6,4 \%$ & $9,3 \%$ \\
$2000-2599$ & $12,3 \%$ & $10,4 \%$ & $12,0 \%$ & $12,7 \%$ & $7,3 \%$ & $9,1 \%$ \\
$2600-3199$ & $15,1 \%$ & $15,8 \%$ & $14,7 \%$ & $24,2 \%$ & $11,9 \%$ & $13,4 \%$ \\
$3200-3999$ & $11,8 \%$ & $15,8 \%$ & $12,1 \%$ & $11,5 \%$ & $12,9 \%$ & $13,1 \%$ \\
$4000-4999$ & $12,0 \%$ & $14,8 \%$ & $12,2 \%$ & $13,1 \%$ & $14,4 \%$ & $12,9 \%$ \\
$5000-7499$ & $10,0 \%$ & $10,9 \%$ & $10,3 \%$ & $8,8 \%$ & $14,8 \%$ & $12,6 \%$ \\
\hline$>7500$ & $10,3 \%$ & $6,0 \%$ & $10,7 \%$ & $8,5 \%$ & $18,7 \%$ & $15,9 \%$ \\
\hline Total & $7,4 \%$ & $6,6 \%$ & $7,1 \%$ & $5,0 \%$ & $11,0 \%$ & $9,6 \%$ \\
\hline
\end{tabular}

Quellen: Scientific Use-files des Mikrozensus 2005, 2006 und EVS 2003; SAVE 2005 und 2006.

Bemerkung: Mikrozensus und EVS Stichproben auf Individuen über 17 Jahre beschränkt.

(*) Prozentsatz bezieht sich auf beobachtete Werte (ohne Missings).

${ }^{1}$ Gewichtet mit Hochrechnungsfaktoren für Deutschland.

\footnotetext{
${ }^{34} \mathrm{H}_{0}$ : Stichproben haben identische relative Häufigkeitsverteilungen (Testquelle: Glenberg, Andrzejewski, 2008, S. 513 ff). $\mathrm{H}_{0}$ wird verworfen für SAVE und Mikrozensus 2005 mit $\alpha=1 \%$ durch Kategorie der Selbständigen. Ebenso wird $\mathrm{H}_{0}$ für SAVE und Mikrozensus 2006 sowie EVS 2003 und Mikrozensus 2005 mit $\alpha=1 \%$ verworfen, wobei SAVE eine wesentlich niedrigere $\mathrm{chi}^{2}$ Statistik hat.

${ }^{35} \mathrm{H}_{0}$ kann nicht verworfen werden für SAVE und Mikrozensus 2005 mit $\alpha=10 \% . \mathrm{H}_{0}$ wird verworfen für SAVE und Mikrozensus 2006 mit $\alpha=1 \%$ durch Kategorie 2000-2599€. $\mathrm{H}_{0}$ wird verworfen für EVS 2003 und Mikrozensus 2005 mit $\alpha=1 \%$ durch mehrere Kategorien.
} 
Tabelle 13: Soziodemographische Merkmale der Selbständigen in SAVE, Mikrozensus und EVS

\begin{tabular}{|c|c|c|c|c|c|c|}
\hline & \multicolumn{2}{|c|}{2005} & \multicolumn{2}{|c|}{2006} & 2003 & 2003 \\
\hline Geschlecht & SAVE & Mikrozensus & SAVE & Mikrozensus & EVS & $\mathrm{EVS}^{1}$ \\
\hline männlich & $63,2 \%$ & $69,6 \%$ & $63,0 \%$ & $69,0 \%$ & $69,2 \%$ & $69,4 \%$ \\
\hline weiblich & $36,8 \%$ & $30,4 \%$ & $37,0 \%$ & $31,0 \%$ & $30,8 \%$ & $30,7 \%$ \\
\hline \multicolumn{7}{|l|}{ Haushaltsgröße } \\
\hline 1 & $7,9 \%$ & $17,9 \%$ & $8,5 \%$ & $19,0 \%$ & $11,5 \%$ & $20,4 \%$ \\
\hline 2 & $36,8 \%$ & $33,0 \%$ & $45,5 \%$ & $32,7 \%$ & $30,0 \%$ & $28,9 \%$ \\
\hline 3 & $24,7 \%$ & $21,3 \%$ & $18,7 \%$ & $21,1 \%$ & $20,4 \%$ & $19,7 \%$ \\
\hline 4 & $19,9 \%$ & $19,8 \%$ & $18,0 \%$ & $19,1 \%$ & $23,8 \%$ & $20,0 \%$ \\
\hline 5 & $8,6 \%$ & $6,0 \%$ & $7,1 \%$ & $6,2 \%$ & $9,9 \%$ & $7,8 \%$ \\
\hline$>=6$ & $2,1 \%$ & $2,0 \%$ & $2,1 \%$ & $1,9 \%$ & $4,4 \%$ & $3,2 \%$ \\
\hline \multicolumn{7}{|l|}{ Altersklassen } \\
\hline$<30$ & $5,5 \%$ & $6,4 \%$ & $9,0 \%$ & $6,4 \%$ & $2,3 \%$ & $2,6 \%$ \\
\hline $30-39$ & $23,4 \%$ & $22,8 \%$ & $20,1 \%$ & $21,7 \%$ & $24,5 \%$ & $25,6 \%$ \\
\hline $40-49$ & $30,9 \%$ & $33,3 \%$ & $26,1 \%$ & $33,8 \%$ & $38,3 \%$ & $36,1 \%$ \\
\hline $50-59$ & $22,7 \%$ & $24,2 \%$ & $23,2 \%$ & $24,9 \%$ & $26,0 \%$ & $24,9 \%$ \\
\hline$>=60$ & $17,5 \%$ & $13,3 \%$ & $21,6 \%$ & $13,3 \%$ & $9,0 \%$ & $10,3 \%$ \\
\hline Mittwelwert Alter & 47,3 & 46,2 & 47,9 & 46,4 & 46,0 & 46,0 \\
\hline Percentile 25 & 38 & 38 & 38 & 39 & 39 & nicht erlaubt \\
\hline Percentile 50 & 46 & 45 & 48 & 46 & 45 & nicht erlaubt \\
\hline Percentile 75 & 55 & 54 & 58 & 54 & 53 & nicht erlaubt \\
\hline \multicolumn{7}{|l|}{ Familienstand } \\
\hline ledig & $17,2 \%$ & $23,2 \%$ & $17,1 \%$ & $23,6 \%$ & $16,0 \%$ & $22,5 \%$ \\
\hline verheiratet & $75,9 \%$ & $66,1 \%$ & $72,0 \%$ & $65,3 \%$ & $75,7 \%$ & $66,7 \%$ \\
\hline verwitwet & $0,3 \%$ & $1,9 \%$ & $1,9 \%$ & $2,2 \%$ & $0,8 \%$ & $1,0 \%$ \\
\hline geschieden & $6,5 \%$ & $8,8 \%$ & $9,0 \%$ & $8,9 \%$ & $7,5 \%$ & $9,8 \%$ \\
\hline \multicolumn{7}{|l|}{ Deutsche Staatsbürgerschaft } \\
\hline $\mathrm{ja}$ & $94,8 \%$ & $93,6 \%$ & $96,2 \%$ & $93,6 \%$ & $98,2 \%$ & $98,4 \%$ \\
\hline nein & $5,2 \%$ & $6,4 \%$ & $3,8 \%$ & $6,4 \%$ & $1,8 \%$ & $1,6 \%$ \\
\hline \multicolumn{7}{|l|}{ Bildungsabschluss } \\
\hline Haupt-(Volks-)schule & $24,1 \%$ & $27,2 \%$ & $21,1 \%$ & $26,6 \%$ & nicht gefragt & nicht gefragt \\
\hline Polytechnische Oberschule & $15,8 \%$ & $8,0 \%$ & $10,7 \%$ & $8,1 \%$ & nicht gefragt & nicht gefragt \\
\hline Realschule (Mittlere Reife) & $21,0 \%$ & $20,2 \%$ & $21,3 \%$ & $20,6 \%$ & nicht gefragt & nicht gefragt \\
\hline Fachhochschule & $6,2 \%$ & $8,1 \%$ & $8,5 \%$ & $8,2 \%$ & nicht gefragt & nicht gefragt \\
\hline Abitur & $33,0 \%$ & $34,5 \%$ & $38,4 \%$ & $34,9 \%$ & nicht gefragt & nicht gefragt \\
\hline ohne Angabe/ entfällt & $0,0 \%$ & $1,8 \%$ & $0,0 \%$ & $1,7 \%$ & nicht gefragt & nicht gefragt \\
\hline
\end{tabular}

Quellen: Scientific Use-files des Mikrozensus 2005, 2006 und EVS 2003; SAVE 2005 und 2006.

Bemerkung: Mikrozensus und EVS Stichproben auf Individuen über 17 Jahre beschränkt.

${ }^{1}$ Gewichtet mit Hochrechnungsfaktoren für Deutschland. 


\section{Anhang C: Weitere Anmerkungen zur Stichprobe}

Stichprobenbegrenzung: Da für diese Untersuchung plausible Werte für Einkommen und Ersparnis wichtig sind, wurden all diejenigen Haushalte gelöscht, deren Angaben zu einem negativen Konsum des Haushaltes geführt hätten. Dazu wurde das durchschnittliche Monatsnettoeinkommen mit 12 multipliziert und größere außergewöhnliche Einkünfte (Schenkung, Lotteriegewinn, Gewinnausschüttung etc) oder Erbschaften ohne die Erbschaft eines Hauses oder Grundstücks addiert. Die Erbschaft eines Hauses oder Grundstückes wird nicht addiert, da ein Verkauf stattfinden müsste, um anderen Konsum außer Wohnkonsum daraus zu ziehen. Würde die Erbschaft eines Hauses bzw. eines Grundstückes auch addiert, so ergäbe sich ein nur sehr geringer Unterschied von zwei Haushalten in der Stichprobe. Anschließend wurde die Ersparnis des Jahres subtrahiert. Von den 11.318 Beobachtungen auf Haushaltsebene von 2005-2008 mussten 61 Beobachtungen (ca. 0,5\%) gelöscht werden.

Erfassung des Berufsstandes: Der erfasste Berufsstand sich bezieht auf den Zeitpunkt der Befragung selbst. Ein Wechsel während des Jahres in einen anderen Berufsstand könnte daher für die Aussagekraft der Daten ein Problem darstellen. In SAVE gibt es allerdings Möglichkeiten in eingeschränktem Maße für einen eventuellen Wechsel des Berufstandes während des Jahres zu kontrollieren. Die Dummyvariable „Einkommen aus selbständiger Tätigkeit“, die sich auf die Einkommensarten im Dezember des Vorjahres bezieht, kann dazu herangezogen werden. Somit könnte der selbständigen Status eines Jahres gemessen im Befragungszeitraum von normalerweise April bis August mit dieser Dummyvariable des Fragebogens aus dem nächsten Jahr überprüft werden. Da Landwirte, Freiberufler, Gewerbetreibende und sonstige Selbständige Einkommen aus selbständiger Arbeit erzielen, werden die folgenden Angaben auf diese Gruppe bezogen dargelegt (die Hinzunahme von mithelfenden Familienangehörigen hätte das Bild verfälscht). So haben 73\% (2005) / 79\% (2006) / 76\% (2007) der zum Befragungszeitpunkt als selbständig Identifizierten und im Folgejahr erneut Befragten „Einkünfte aus selbständiger Tätigkeit“ auch noch im Dezember.

Diese Zahl wird durch eine weitere untermauert. So beträgt die Korrelation des Selbständigenstatus von einem Jahr auf das andere zwischen 76 und 79\%. Die Angaben beziehen sich abermals auf eine Zusammenfassung der Gruppen der Landwirte, Freiberufler, Gewerbetreibender und sonstige Selbständiger. Nimmt man die für diese Arbeit definierte nicht obligatorisch abgesicherte Selbständigengruppe, reduziert sich die Korrelation auf $68-72 \%$. 


\section{Anhang D: Berechnung des Sparbetrages, der die Grundsicherung im Alter deckt}

Annahmen:

- Grundsicherung im Alter (real): $\mathrm{G}=647 €$ pro Monat

- Inflation bzw. Steigerung der Rente pro Jahr: $\delta=2 \%$

- Nominalzinssatz: $i=4 \%$

- dynamische Lebenserwartung von 65-Jährigen Männern in 2006 (Bevölkerungsannahmen der Rürup-Kommission): $1^{\mathrm{M}=} 16,63$ Jahre

- dynamische Lebenserwartung von 65-Jährigen Frauen in 2006 (Bevölkerungsannahmen der Rürup-Kommission): $1^{\mathrm{W}}=20,28$ Jahre

- für die Haushaltsebene wird das Geschlecht und das Alter der befragten Person genommen

Berechnung des notwendigen Vermögens (V) bei Renteneintritt für Männer mit $\mathrm{l}^{\mathrm{i}}=\mathrm{l}^{\mathrm{M}}$ und Frauen mit $\mathrm{l}^{\mathrm{i}}=1^{\mathrm{W}}$ :

$$
V_{i}=\frac{12 \cdot G \cdot\left(\left(\frac{1+\delta}{1+i}\right)^{i^{i}}-1\right)}{\left(\frac{1}{1+i}\right) \cdot(\delta-i)}
$$

Rechnungswert (RW) für Glättung der jährlichen Ersparnisbeträge mit:

- nominale Aufzinsung von $\mathrm{i}=4 \%$

- Wachstum der Ersparnisbeträge mit $\delta=2 \%$ (Inflation) $+\mathrm{w}=1 \%$ (Reallohnwachstum)

- Erwerbsjahre: 40 Jahre von 25 bis 64 Jahre, d.h. alle gehen mit 65 in Rente: $t=A l t e r-65$ Jahre

- Einzahlung der Ersparnisbeiträge geschieht am Ende des Jahres, Auszahlung der Annuität am Anfang des Jahres

$$
R W=\frac{\left(\frac{1+i}{1+\delta+w}\right)^{40}-1}{\left(\frac{1}{1+\delta+w}\right) \cdot(i-\delta-w)}
$$

Die jährlich notwendige Ersparnis errechnet sich aus:

$$
S_{i}=\frac{V_{i}}{R W}
$$

Die Berechnung der um Inflations- und Reallohnwachstum angepassten jährlichen Sparbeträge ergibt sich aus:

$$
S_{i t}=S_{i} \cdot\left(\frac{1}{1+\delta+w}\right)^{t}
$$

Vereinfachte Rückrechnung auf monatliche Basis:

$$
\hat{S}_{i t}=S_{i t} / 12
$$




\section{Anhang E: Weitere Tabellen}

\section{Tabelle 14: Haushaltssparquoten über Berufsgruppen (2005-2007)}

\begin{tabular}{|c|c|c|c|c|}
\hline & 2005 & 2006 & 2007 & 2005-2007 \\
\hline \multicolumn{5}{|c|}{ individuelle Durchschnittssparquoten } \\
\hline \multirow[t]{2}{*}{ abh. Beschäftigte } & $7,7 \%$ & $7,0 \%$ & $7,2 \%$ & $7,2 \%$ \\
\hline & ** & ** & $* *$ & $* * *$ \\
\hline Selbständige & $11,2 \%$ & $10,1 \%$ & $10,2 \%$ & $10,4 \%$ \\
\hline \multicolumn{5}{|c|}{ individuelle Mediansparquoten } \\
\hline abh. Beschäftigte & $3,3 \%$ & $3,7 \%$ & $2,9 \%$ & $3,3 \%$ \\
\hline Selbständige & $5,1 \%$ & $2,9 \%$ & $4,6 \%$ & $4,3 \%$ \\
\hline \multicolumn{5}{|c|}{ Sparquote über Durchschnitte } \\
\hline abh. Beschäftigte & $8,7 \%$ & $7,5 \%$ & $8,0 \%$ & $8,0 \%$ \\
\hline Selbständige & $12,5 \%$ & $12,1 \%$ & $10,6 \%$ & $11,7 \%$ \\
\hline
\end{tabular}

Quelle: Eigene Berechnung. SAVE 2005-2008. Imputierte Datensätze mit Nr. 1.

Einkommen ohne außergewöhnliche Einkünfte.

ttest $\mathrm{H}_{0}: \mathrm{MW}_{\mathrm{B}}<\mathrm{MW}_{\mathrm{S}} ; *: 10 \%$ Signifikanzlevel; ** : $5 \%$; *** : $1 \%$. 


\section{Discussion Paper Series}

Mannheim Research Institute for the Economics of Aging, Universität Mannheim

To order copies, please direct your request to the author of the title in question.

\begin{tabular}{|c|c|c|c|}
\hline Nr. & Autoren & Titel & Jahr \\
\hline $175-09$ & $\begin{array}{l}\text { Steffen Reinhold, } \\
\text { Hendrik Jürges }\end{array}$ & Parental Income and Child Health in Germany & 09 \\
\hline $176-09$ & $\begin{array}{l}\text { Karsten Hank, Marcel } \\
\text { Erlinghagen }\end{array}$ & $\begin{array}{l}\text { Perceptions of Job Security in Europe's Ageing } \\
\text { Workforce }\end{array}$ & 09 \\
\hline $177-09$ & $\begin{array}{l}\text { Hendrik Jürges, } \\
\text { Karsten Hank, }\end{array}$ & $\begin{array}{l}\text { The Last Year of Life in Europe: Initial findings } \\
\text { from the SHARE study }\end{array}$ & 09 \\
\hline $178-09$ & Steffen Reinhold & $\begin{array}{l}\text { Reassessing the Link between Premarital } \\
\text { Cohabitation and Marital Instability }\end{array}$ & 09 \\
\hline $179-09$ & $\begin{array}{l}\text { Alexander Ludwig, } \\
\text { Edgar Vogel }\end{array}$ & $\begin{array}{l}\text { Mortality, Fertility, Education and Capital } \\
\text { Accumulation in a simple OLG Economy }\end{array}$ & 09 \\
\hline $180-09$ & Edgar Vogel & $\begin{array}{l}\text { From Malthus to Modern Growth: Child Labor, } \\
\text { Schooling and Human Capital }\end{array}$ & 09 \\
\hline $181-09$ & $\begin{array}{l}\text { Steffen Reinhold, } \\
\text { Hendrik Jürges }\end{array}$ & $\begin{array}{l}\text { Secondary School Fees and the Causal Effect } \\
\text { of Schooling on Health Behaviour }\end{array}$ & 09 \\
\hline $182-09$ & $\begin{array}{l}\text { Steffen Reinhold, } \\
\text { Kevin Thom }\end{array}$ & $\begin{array}{l}\text { Temporary Migration and Skill Upgrading: } \\
\text { Evidence from Mexican Migrants }\end{array}$ & 09 \\
\hline $183-09$ & $\begin{array}{l}\text { Hendrik Jürges, } \\
\text { Eberhard Kruk, Steffen } \\
\text { Reinhold }\end{array}$ & $\begin{array}{l}\text { The effect of compulsory schooling on health - } \\
\text { evidence from biomarkers }\end{array}$ & 09 \\
\hline $184-09$ & \begin{tabular}{|l} 
Nicola Fuchs- \\
Schündeln, Dirk \\
Krüger, Mathias \\
Sommer
\end{tabular} & $\begin{array}{l}\text { Inequality Trends for Germany in the Last Two } \\
\text { Decades: A Tale of Two Countries }\end{array}$ & 09 \\
\hline $185-09$ & $\begin{array}{l}\text { Francesco Cinnirella, } \\
\text { Joachim Winter }\end{array}$ & $\begin{array}{l}\text { Size Matters! Body Height and Labor Market } \\
\text { Discrimination: A Cross-European Analysis }\end{array}$ & 09 \\
\hline $186-09$ & $\begin{array}{l}\text { Hendrik Jürges, } \\
\text { Steffen Reinhold, } \\
\text { Martin Salm }\end{array}$ & $\begin{array}{l}\text { Does Schooling Affect Health Behavior? } \\
\text { Evidence from Educational Expansion in } \\
\text { Western Germany }\end{array}$ & 09 \\
\hline $187-09$ & Michael Ziegelmeyer & $\begin{array}{l}\text { Das Altersvorsorge-Verhalten von } \\
\text { Selbständigen - eine Analyse auf Basis der } \\
\text { SAVE-Daten }\end{array}$ & 09 \\
\hline
\end{tabular}

